\title{
Size-dependency of Concrete-Filled Steel Tubes subject to Impact Loading
}

\author{
Mahsa Mirmomeni ${ }^{1}$, Amin Heidarpour ${ }^{1}$, Xiao-Ling Zhao $^{1}$, Riadh Al-Mahaidi ${ }^{2}$, Jeffrey A. \\ Packer $^{3}$ \\ ${ }^{1}$ Department of Civil Engineering, Monash University, Melbourne, VIC 3800, Australia \\ ${ }^{2}$ Department of Civil and Construction Engineering, Swinburne University of Technology, \\ VIC 3122, Australia \\ ${ }^{3}$ Department of Civil Engineering, University of Toronto, Toronto, Ontario M5S 1A4, Canada
}

Submitted to: International Journal of Impact Engineering 


\section{Abstract}

With the increasing trend towards using concrete-filled steel tubes (CFST) in civil 44 structures, understanding their mechanical properties under impact loads has attracted the

45 interest of researchers. The dynamic properties of concrete confined by steel tubes are size46 dependent. An experimental program was carried out to investigate the relation between the 47 size and impact response of CFST sub-samples. High-strain-rate tests were conducted on 48 specimens made from self-consolidating normal concrete confined by mild steel tubes. To 49 take into account the stress uniformity and confinement effects in the specimens, various 50 height-to-diameter ratios (H/D) and diameter-to-tube-wall thickness ratios $(D / t)$ were 51 considered. Dynamic Increase Factors (DIFs) were derived as the ratio of the material 52 strength at high strain rate to those of the same size under quasi-static loading conditions. The 53 results were compared to two sets of reference tests, namely unconfined concrete and hollow 54 steel tube specimens of the same size and with the same boundary conditions. The results 55 indicate the influence of $H / D$ ratio, $D / t$ ratio, and end-friction coefficient on the stress-strain 56 distribution, dynamic compressive properties and failure modes of sub-scale concrete-filled 57 steel tubes under impact load. The size-dependent behaviour of the CFST is found to be a 58 function of the level of confinement the circumferential steel tube imposes on the concrete 59 filling. Two expressions are proposed for predicting the DIF of yield stress for CFSTs: one 60 considering the concrete-steel interaction relationship presented in Eurocode 4, and an 61 empirical expression based on the Cowper-Symonds model for steel. The proposed rate- and 62 size-dependent expressions show close correlations with experimental results.

63 Keywords Concrete-filled steel tubes (CFST); Impact loading; Size dependency; Boundary 64 conditions; Confinement. 


\section{INTRODUCTION}

Civil structures not only bear conventional loads but may also be subjected to extreme

68 loading conditions, such as those associated with impact and collision incidents [1-9].

69 Increasing concern in the engineering community to design protective structures have

70 necessitated the accurate understanding of the dynamic properties of construction materials

71 [1]. Concrete-filled steel tube (CFST) columns have wide application in the construction

72 industry due to their inherent capability to significantly increase the load-carrying capacity

73 and ductility of concrete as well as their structural and economic advantages over open and

74 empty steel sections. Such qualities can be a potential merit in developing impact/blast-

75 resistant structures. These composite columns utilise the most favourable properties of the

76 constituent materials: concrete and steel. Nevertheless, they have the individual

77 characteristics of these materials, such as size- and rate-dependency.

78 Experimental investigations reported in the literature have demonstrated the behaviour of

79 normal concrete and concrete-filled steel tubes under impact loading conditions [10-12]. The

80 most evident behaviour is the increase of strength at a higher strain rate, which is known as

81 the Dynamic Increase Factor $(D I F)$, or the ratio of dynamic strength to quasi-static strength.

82 Prichard and Perry [13] performed CFT impact experiments using a drop hammer apparatus.

83 Xiao et al. [14] applied the split Hopkinson pressure bar (SHPB) to study the mechanical

84 behaviour of CFT under high-speed impact load. All these existing studies show some merits

85 of CFT in resisting dynamic loads compared with conventional reinforced or plain concrete.

86 Due to the inherent size dependency of concrete, finding consistency in the results of these

87 studies is challenging.

88 A large number of experimental results have indicated that the compressive strength of 89 concrete decreases when the specimen size increases. Bischoff and Perry [11] illustrated that 90 the size effect influences the behaviour of unconfined concrete under static and impact 
91 compressive load. This size dependence is mostly a result of the heterogeneity of and local 92 damage to the concrete material [15]. In the case of high strain-rate tests, to achieve a 93 uniform state of stress along the specimen length, the specimen should be sufficiently short. 94 However, a shorter specimen results in significant end-friction effects and leads to an 95 apparent strength increase [11]. Ross et al. [16] found that the load-carrying capacity of 96 concrete increases substantially at higher strain rates, possibly due to inertial effects and 97 resistance to crack opening. In contrast to concrete, steel is a relatively homogeneous ductile 98 material with a negligible size effect on its mechanical properties [1]. Yu et al. [17] proved 99 that confining steel tubes not only affect the axial load, flexural moment and shear capacity of 100 the concrete core, but also take the role of lateral reinforcement.

101 To understand the influence of different experimental factors on the dynamic 102 compressive properties of concrete, Hao et al. [18] presented an experimental investigation of 103 the influences of lateral inertia confinement, end-friction confinement and aggregates in high104 speed impact tests on the dynamic increase factor $(D I F)$. They confirmed that lateral inertia 105 and end-friction confinement effects are dependent on the specimen's diameter and strain 106 rate. More recently, Huo et al. [19] conducted impact tests investigating the influence of 107 slenderness ratios, ranging from 0.3 to 1.0 , on the dynamic behaviour of CFT at elevated 108 temperatures and showed that slenderness ratios from 0.3 to 1.0 did not have an obvious 109 effect on the axial elastic stiffness and yield strengths of the CFT columns. Micro-sized $11032 \mathrm{~mm}$ specimens with biggest aggregate size of $5 \mathrm{~mm}$ were used and their results 111 demonstrated that the aggregate size and specimen size influence the dynamic behaviour of 112 CFT under impact loading.

113 The main objective of this research program is to investigate the size-effect phenomenon 114 on self-compacting unconfined concrete and steel-tube-confined concrete, subject to high 115 strain rate loading. To date, this has not been investigated. Self-compacting concrete (SCC) is 
116 a relatively new kind of high-performance concrete, with excellent deformability and 117 segregation resistance, and is a popular choice for confined concrete, especially concrete118 filled steel tubes [20]. The elastic modulus, creep and shrinkage of SCC are similar to those 119 of normal concrete [21]. In addition, constructing with SCC rather than normal concrete can 120 eliminate the need for vibration as well as being cost-effective.

121 In this study, servo-hydraulic testing machines were utilized to induce lower rates of 122 strain for dynamic impact tests, to provide evidence on how the size effect influences the 123 strength of samples of self-compacting unconfined and concrete-filled steel tubes (CFSTs). 124 The compressive resistances were compared with those attained from a similar series of 125 quasi-static experiments. Moreover, the prominent effects of other factors, such as level of 126 confinement, end-boundary conditions (non-greased and greased ends), and curing conditions 127 (water-cured and air-cured), which result in different compressive strengths, were 128 investigated. New expressions, which take into account the effects of loading rate and size of 129 the contributing steel and concrete components, to determine the increased dynamic strength 130 of CFST, are also proposed. Moreover, various observed failure modes for samples with 131 different sizes, during quasi-static and impact tests, are discussed.

\section{EXPERIMENTAL INVESTIGATION}

134 An experimental study was performed to assess the size dependency of mesoscale 135 concrete- filled mild steel tubular columns under uniaxial impact rates of loading. Initial tests 136 were also conducted on the constituent materials, including standard tensile tests on coupons 137 extracted from the mild steel seamless tubes and standard compression tests on cylindrical 138 concrete specimens $(100 \times 200 \mathrm{~mm})$, at quasi-static rates within prescribed standard ranges. 


\subsection{Concrete mixture}

Self-compacting concrete (SCC) with a target strength grade of C37 was selected for both

141 impact and static compression tests. According to the European Guidelines for Self-

142 Compacting Concrete [22], self-compacting concrete is produced with a high powder content

143 and a low water/powder ratio. Therefore,

144 1) Ordinary Portland cement and local water were utilized at a $w / c$ (water/cement)

2) Sand was chosen as the fine aggregate with the content being $52 \%$ of the total aggregate weight, which is within the standard range of $48 \%-55 \%$ of total aggregate weight.

3) The content of coarse aggregate with a maximum particle size of a quarter inch $(6.35 \mathrm{~mm})$ size was $32.8 \%$ of the weight, which is within the standard range of $27 \%$ $36 \%$ [22]. Since the surface moisture content of aggregates has an effect on concrete strength, oven-dried aggregates were used each time when making SCC. Based on AASHTO-T84 [23] and ACI [23], the water absorption (WA) of aggregates was taken into consideration in the design of the amount of water in the SCC mix.

4) Based on ASTM-C618 [25], Class F fly ash $\left(0.533 \mathrm{~kg} / \mathrm{m}^{3}\right)$ is suitable for SCC to increase the cohesion and reduce the sensitivity to changes in water content, so this was also utilized.

5) Glenium 107 Suretec (MasterGlenium Sky 807) manufactured by BASF was used as the super-plasticizer to increase the workability of SCC and to avoid segregation.

161 The average 28-day compressive strength $\left(f_{c}\right)$ of the resulting standard cylinders was $63 \mathrm{MPa}$. 


\subsection{Steel material properties}

Three standard tensile coupons were taken from Grade 250 seamless steel pipes and tested according to the Australian Standard AS 1391 [26]. The average mechanical properties

165 of the tensile coupons tested are presented in Table 1.

Table 1. Tensile coupon test results

\begin{tabular}{|l|l|l|}
\hline Yield stress $\left(f_{0.2 \%}\right)$ & $315 \mathrm{MPa}$ & \\
\hline Ultimate tensile stress $\left(f_{u}\right)$ & $455 \mathrm{MPa}$ & \\
\hline Elastic modulus $(E)$ & $200 \mathrm{GPa}$ & \\
\hline
\end{tabular}

\subsection{Casting and curing conditions}

While SCC was cast in the hollow steel tubes for the main tests, unconfined specimens

171 for the control tests were cast in PVC tubes. The hollow steel tubes were filled with concrete

172 by hand without the need for any vibration. The final top surface was smoothed off using a

173 hand trowel and covered with a nylon film. Specimens were kept in plastic, covered at room 174 temperature for 7 days, and subsequently cured in the air for up to 28 days [11, 27]. The 175 unconfined samples were mostly water-cured, that is, after curing at room temperature in 176 plastic-covered conditions over 24 hours, samples were removed from the PVC tubes and 177 cured in a water tank for 7 days and then at room temperature until the testing date at 28 days.

178 In order to make a comparison and verify the effect of curing conditions on the test results, a 179 set of unconfined samples were covered with plastic at room temperature for 7 days and 180 subsequently air-cured (AC) at room temperature until the 28th day. The PVC tubes were left 181 around the specimens until the day of testing to achieve similar conditions to those for CFST 182 curing. 


\subsection{Specimen sizes}

The geometric properties for all the specimens are listed in Table 2. For the concrete-

185 filled steel tube samples, there were two different inner diameter sizes: $50 \mathrm{~mm}$ and $40 \mathrm{~mm}$ with

186 height/diameter $(R=H / D)$ ratios of 2 and 1 . For each CFST sample size, as shown in Table 2,

187 the wall thicknesses (WTs) of the steel tube samples were 1,2 and $3 \mathrm{~mm}$. According to ACI

188 Committee 318 [28], the maximum aggregate size should not exceed one quarter of the

189 minimum dimension of the structural component's cross-section. Hence, the quarter-inch

190 aggregates used in the design mix are appropriate for the specimen sizes considered here. The

191 outer surfaces of the manufactured steel tubes were carefully machined down to achieve the

192 wall thicknesses mentioned above. Care was taken to ensure that deviation from the target

193 wall thickness was negligible throughout each specimen.

Table 2. Plain concrete and CFST specimen sizes

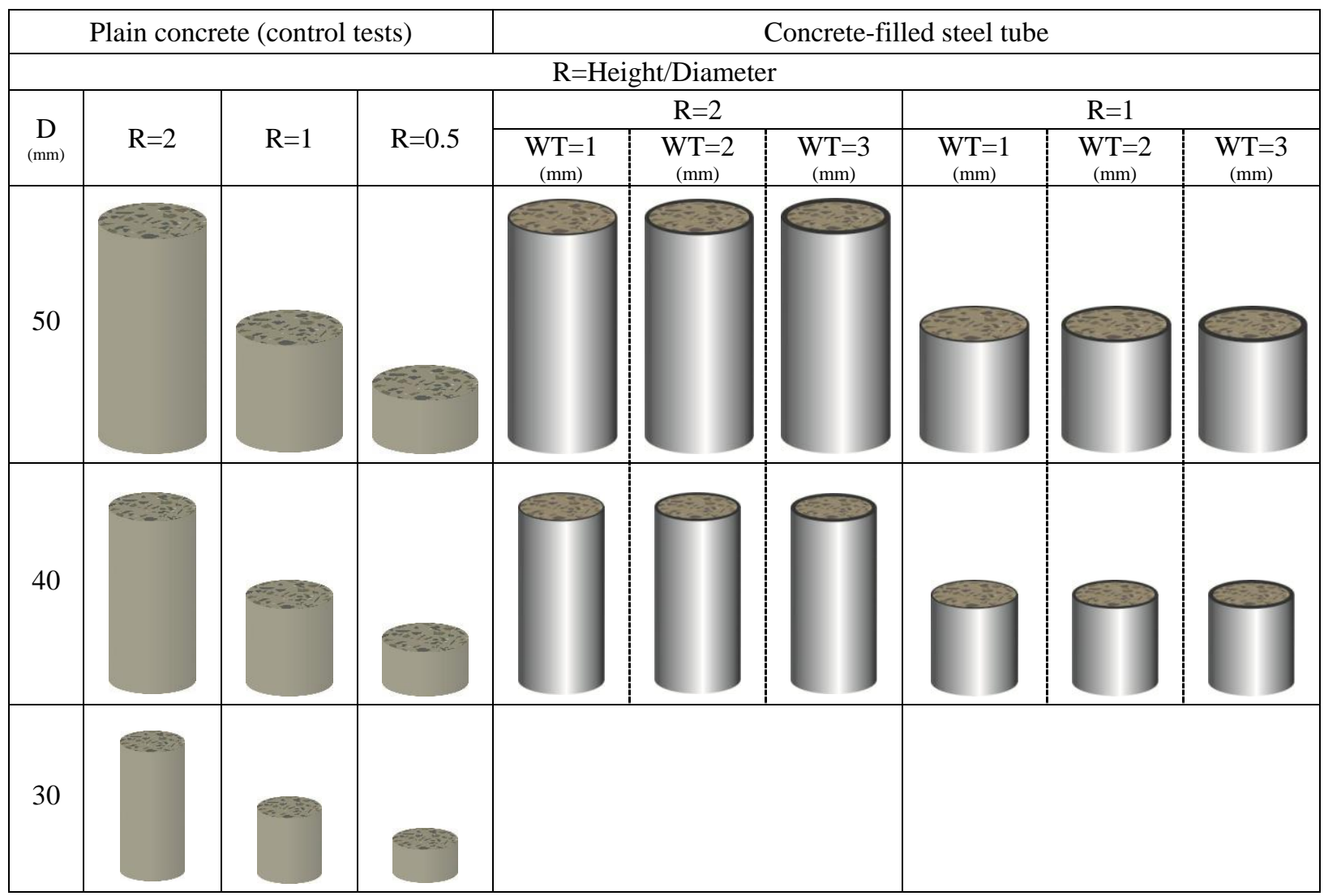


196 It is well established that the larger the height/diameter ratio, the smaller the confinement 197 effects from frictional forces and the longer it will take for the stress wave to reflect between 198 the specimen ends to achieve a uniform state of stress along the specimen length [11]. Hence, 199 for the control unconfined concrete tests, there were three different diameter sizes: $50 \mathrm{~mm}$, $20040 \mathrm{~mm}$ and $30 \mathrm{~mm}$ with aspect ratios of 2,1 and 0.5 . The aspect ratios $(H / D)$ were chosen so as 201 to reduce end-effects and to ensure that the specimens were stub columns with negligible 202 effects of column slenderness [29]. The range of aspect ratios can help demonstrate the 203 opposing effects of confinement and inertia. Additional diameters and aspect ratios to those 204 of the CFST sample sizes were chosen to cover a wider range for the size-dependency effect 205 on SCC. A second set of control specimens consisted of hollow steel tubes of the same size as 206 those used for making the CFSTs. All tests conducted on CFSTs were also conducted on 207 hollow tubes of the same size and under the same loading rate conditions.

To ensure the consistency of results, for each size and each test type, at least 3 samples of 209 the CFSTs and 6 samples of the plain concretes were cast. Overall, 216 water-cured 210 unconfined, 24 air-cured unconfined, and 72 steel-tube-confined samples were cast, cured, 211 surface machined, and tested on the 28th day. Testing arrangements, instrumentation and 212 procedure

Prior to testing, both ends of the samples were ground smooth and flat using a grinding 215 wheel with diamond cutters. This was to ensure that the axial load was applied evenly to the 216 entire cross-section and that the concrete and steel were simultaneously loaded. The accurate 217 diameter and height dimensions of the specimens were recorded after grinding the top and 218 bottom surfaces of the cylinders. Top and bottom rigid steel end platens were employed in 219 order to distribute the applied load uniformly over both the concrete and steel sections. All 220 specimens were placed centrally in the testing machine with minimum misalignment to 221 ensure pure axial loading. 
The test program was carried out in the Civil Engineering Laboratory at Monash

223 University and the Smart Structures Laboratory at Swinburne University of Technology. The

224 specimens were tested in one of two testing machines as shown in Figure 1. For the plain

225 concrete and steel hollow tube control tests, an Instron $8802250 \mathrm{kN}$ servo-hydraulic testing

226 machine was used. However, due to the insufficient capacity of this Instron machine for the

227 CFST specimens, tests on those were performed on a 1MN MTS-311 servo-hydraulic 228 machine.

229

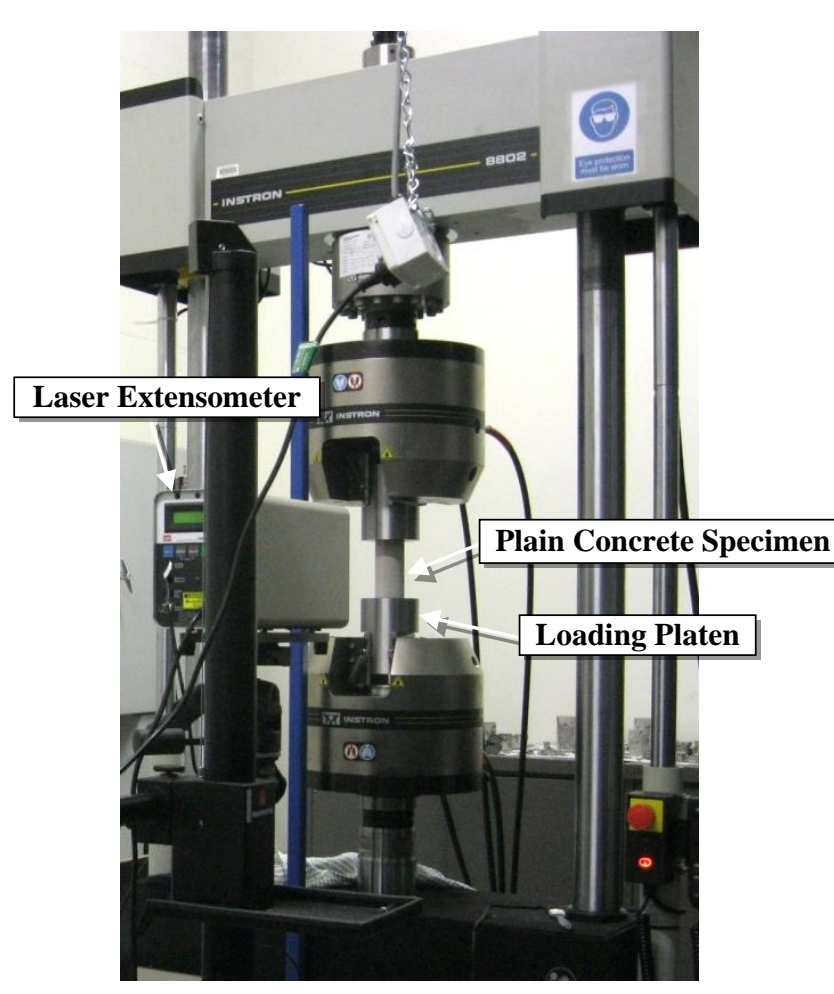

(a)

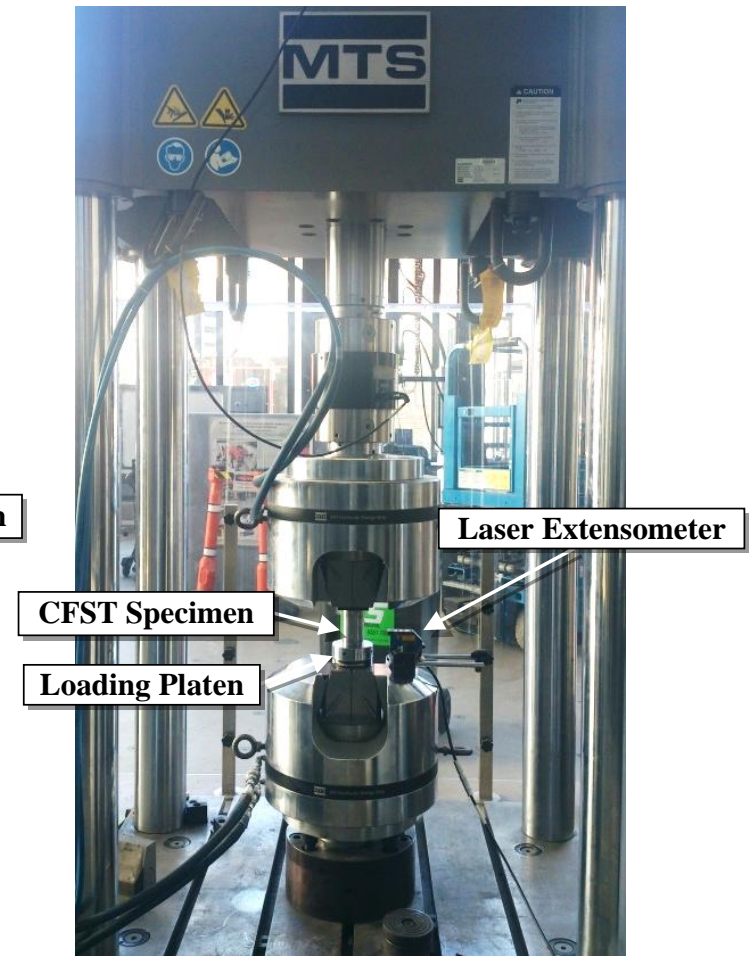

(b)

Figure 1. Test set-up (a) 250kN Intron 8802 at Monash University and (b) 1MN MTS-311 at Swinburne University of Technology

The loading rate for the high strain-rate tests was $150 \mathrm{~mm} / \mathrm{s}$. Static compression testing at a rate of $0.1 \mathrm{~mm} / \mathrm{min}$ was conducted for comparison with the high strain-rate (HSR) tests in this study. The specimens in both static and dynamic tests had the same cross-section, wall thickness-to-diameter and aspect ratios. 
For the HSR tests, a $0.5 \mathrm{~mm}$ gap between the steel platen and the top surface of the

243 specimen was assigned for the actuator to accelerate to the desired compression rate and a

244 constant loading rate was achieved before the steel platen first came into contact with the

245 concrete. The average strain rate applied on the specimen can be calculated as:

$246 \dot{\varepsilon}=V_{\text {peak }} / H$

247 where, $V_{\text {peak }}$ is the peak value of the velocity and $H$ is the height of the specimen.

248 It is worth re-emphasising that concrete and steel were loaded simultaneously, such that

249 the behaviour of the concrete-filled steel tube was investigated. In order to reduce the friction

250 of contact surfaces, the top and bottom surfaces of the CFST were lined with a high-

251 performance and high load-carrying grease. Care was taken to apply a thin and uniform layer

252 of grease to avoid initial slippage of samples during the high-strain-rate tests. The effect of 253 end-boundary conditions on the test results was also investigated using two tests: with and

254 without greased end surfaces for the plain concrete tests.

255 Direct strain measurements were obtained using an MTS LX500 non-contact laser 256 extensometer and a Micro-Epsilon opto NCDT 1700 laser sensor, both with high acquisition 257 rate capabilities. The instantaneous strain rate was calculated using the in-time strain readings 258 obtained from these extensometers. A high speed camera was also used for recording 259 concrete failures, particularly during high-strain-rate tests.

\section{RESULTS AND DISCUSSION}

The experimental and analytical results for size-effect dependency of thin-walled concrete- filled steel tubes under impact loading conditions are presented in this section. The

264 first part is devoted to the experimental results of the control tests, i.e. plain SCC and hollow 265 mild steel tubes. The obtained results are compared to those available in the literature. 
266 Subsequently, the experimental and analytical results of the composite concrete filled mild $267 \quad$ steel tubes tests are provided and discussed.

\subsection{Dynamic strength increase factor (DIF) of Concrete}

A number of research efforts have been devoted to the effect of strain rate on concrete. Based on experimental results, some empirical formulae have been developed and reported in the literature. There are many kinds of expressions for the DIF of concrete, such as the exponential function and logarithmic function. The choice of function should be based on the quasi-static strength of concrete and the domain of strain rate needed. One of the most commonly used is a strain-rate-induced strength increase model recommended by CEB [30] for concrete in compression, which is valid for all strain rates:

$$
D I F_{c}=\frac{f_{c d}}{f_{c s}}= \begin{cases}\left(\frac{\dot{\varepsilon}}{\dot{\varepsilon}_{s}}\right)^{1.026 \alpha_{s}} & \dot{\varepsilon} \leq 30 s^{-1} \\ \gamma_{s}\left(\frac{\dot{\varepsilon}}{\dot{\varepsilon}_{s}}\right)^{1 / 3} & \dot{\varepsilon}>30 s^{-1}\end{cases}
$$

where, $f_{c s}$ and $f_{c d}$ are the static and dynamic strength of concrete respectively, in MPa, $\dot{\varepsilon}_{s}=30 \times 10^{-6} \mathrm{~s}^{-1}$ and the empirical parameters are taken as $\alpha_{s}=\left(5+9 \frac{f_{c S}}{f_{0}}\right)^{-1}, f_{0}=10 \mathrm{MPa}$, and $\gamma_{s}=10^{\left(6.156 \alpha_{s}-2\right)}$. Herein, the $D I F_{c}$ value for the standard cylinder $(100 \times 200 \mathrm{~mm})$ tested at an impact speed of $150 \mathrm{~mm} / \mathrm{s}$, is calculated as 1.207 . Moreover, to illustrate the size effect, for all plain concrete control samples with sizes shown in Table 2, the $D I F_{c}$ values have been calculated as the ratio of the ultimate compressive stress (UCS) from impact tests to that obtained from the quasi-static tests. Measured strain rates range between 1 and $7 \mathrm{~s}^{-1}$, the magnitudes which are within the region defined as of impact rates of strain [31]. The obtained increase factors are compared to those calculated using the CEB [30] model for the different size samples in Figure 2.

Lateral and axial inertia and friction impose additional constraints and result in an alteration in the stress states [18]. The lateral inertia confinement is dependent on the size of 
290 the tested samples and the rate at which the tests are conducted. Similarly, the end-friction

291 confinement effect is sensitive to the specimen's geometry and strain rate. While the central

292 region of the specimen is in uniaxial compression, depending on the aspect ratio, the end 293 zones are in a complex state of multiaxial compression caused by frictional restraint of the 294 end-loading plates [18]. To investigate this, the specimens of the same size were tested in this 295 study with and without applying grease to the specimen-platen interface, to minimize the 296 influence of end-friction confinement, and the results are presented in Figure 2.

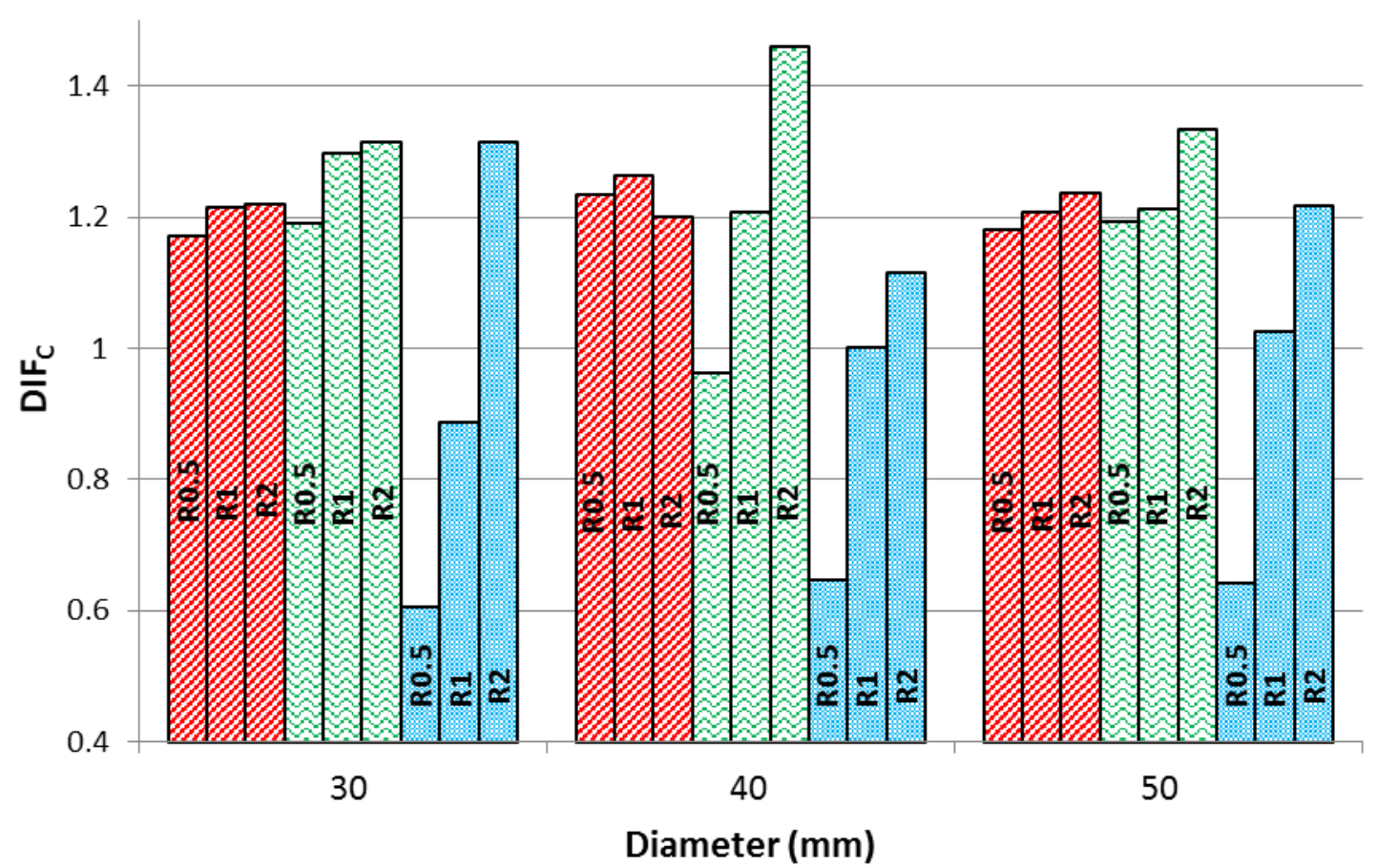

$\square$ Greased Ends $\quad$ UUngreased Ends $\quad$ OCEB

Figure 2. The DIF of ultimate compressive stress $(U C S)$ of plain concrete cylinders with different diameters, aspect ratios $(\mathrm{R}=H / D)$ and end-boundary conditions

Large variations of maximum stresses can be observed based on end-boundary conditions. As Figure 2 shows, cylinders with greased ends all have smaller $D I F_{c}$ values than their ungreased counterparts, with smaller aspect ratios showing the greatest variance. When applying grease on the top and bottom surfaces of specimens, end friction is significantly reduced and lateral expansion of the samples may be aided, resulting in lower capacity. Small 
307 lateral displacement of the sample may be induced due to the reduction of friction, but this 308 does not influence the test result considerably.

Specimens with larger diameters generally have a lower ultimate compressive stress than

310 smaller specimens [32]. This emphasizes that plain concrete specimens of smaller sizes have 311 a more obvious size-effect, and large variations of UCS exist among smaller sized samples

312 [33]. With the decrease of specimen height, end confinement has more effect on the stresses.

313 Hence, as can be seen in Figure 2, taller samples with larger $H / D$ ratios show more rate 314 sensitivity. For samples with a $H / D$ ratio of 1 , the $D I F$ values for diameters of $40 \mathrm{~mm}$ and $31550 \mathrm{~mm}$ are very close to one another, for a specific end-boundary condition. Samples with $316 H / D=0.5$ show the largest variation in $D I F_{c}$, with non-greased values being approximately 317 twice the greased values. While the test results for the ungreased end tests are relatively close 318 to those predicted by the CEB model (mostly $30 \mathrm{~mm}$ and $50 \mathrm{~mm}$ samples), the results of the 319 greased end tests show a considerable difference to those obtained via the CEB model. It is 320 clear that end-boundary conditions play a significant role in the apparent increase in the 321 strength of concrete under axial impact compressive loading, and that the extent of this 322 increase calculated via the CEB model is partly attributed to end confinement. The difference 323 in the increase factor between the CEB predictions and test results for the case of $40 \mathrm{~mm}$ 324 dimeter without greased ends can be attributed to the end confinement friction not being large 325 enough to compensate for the inertia effect. In other words, for this case, the inertia effect 326 becomes more pronounced than friction, counteracting the end friction. In a way that when $327 \mathrm{R}=0.5$, it results in the dynamic strength being lower than that of the static strength in which 328 end friction is the only influencing factor, while substantially increasing the dynamic strength 329 when height increases $(\mathrm{R}=2)$. 
Another important factor that can potentially alter the strength of concrete is the method

331 used for curing the fresh concrete. For research on plain concrete, the common practice is to

332 embed the samples in a water tank for a certain period of time (mostly 7 days). However,

333 water curing is not a practical solution for concrete-filled steel tube elements and the infill

334 concrete is air-cured. To understand the effect of curing on the concrete strengths at quasi-

335 static and high-strain-rate loads, $D I F_{c}$ values of samples with different sizes, cured using the

336 two aforementioned curing methods, are presented in Figure 3. Moreover, for each sample

337 size, the average dynamic ultimate compressive stress $\left(F_{c d}\right)$ and average ultimate compressive

338 stress under quasi-static loading $\left(F_{c s}\right)$ from which the DIF values are calculated have also

339 been presented in this figure.

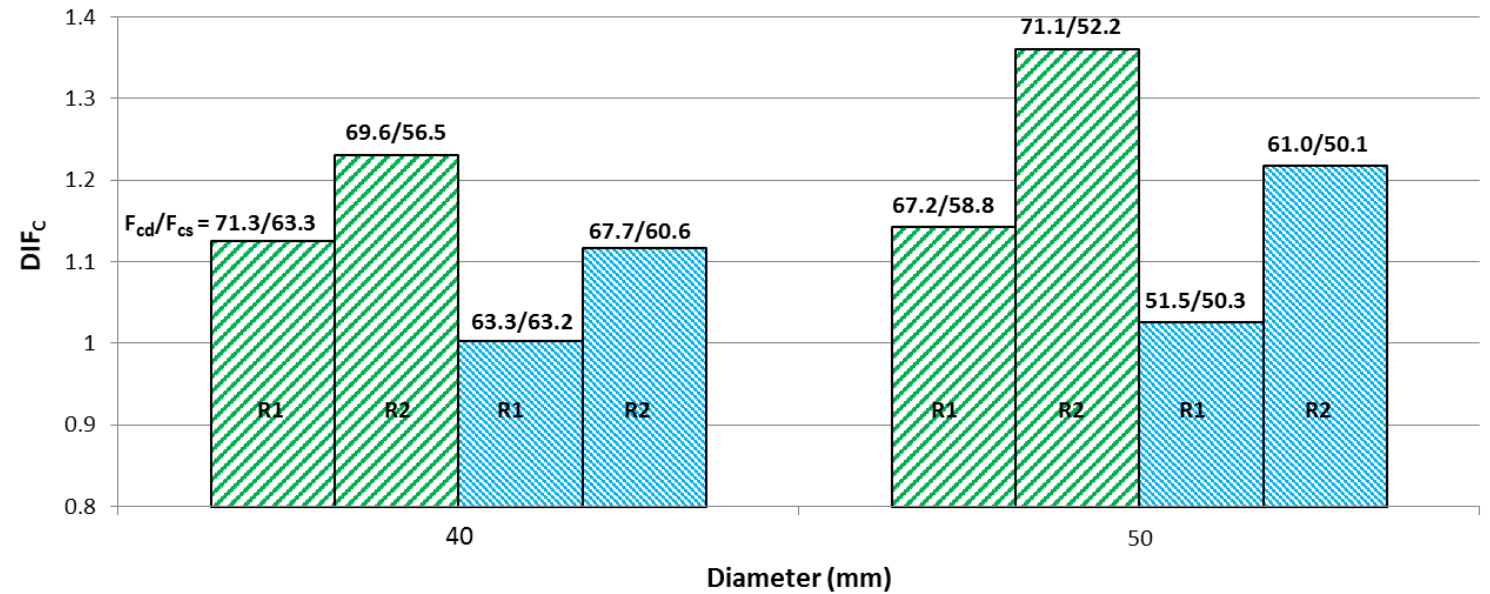

$\square$ Water Cured $\square$ Air Cured

As is evident from the graph, air-cured concretes generally bear larger average maximum stresses and larger increase factors than normally-cured samples. This is attributed to the characteristics of SCC concrete. This is consistent with the results of Zhao et al. [34], who showed that the 28-day strength of SCC specimens fully cured at room temperature is higher than those cured under standard curing conditions. A possible explanation is that air curing has a higher curing temperature than the standard water curing conditions and has sufficient ambient humidity to accelerate the rate of cement hydration and pozzolanic reactions in SCC 
351 [35]. Hence, using the water-cured DIF values yields a more conservative contribution of the 352 plain concrete in this rate effect study.

353

\subsection{Dynamic strength increase factor (DIF) of Steel}

The Cowper-Symonds model [35] is commonly used for the prediction of $D I F_{y}$ for various metals including steel [36]. It is also available in commercial finite element software packages such as LS-DYNA such that:

$$
D I F_{y}=1+(\dot{\varepsilon} / C)^{1 / q}
$$

where $C$ and $q$ are the Cowper-Symonds parameters. A modified Cowper-Symonds model is proposed by Luecke et al. [37] for steels with nominal yield stresses ranging from $248 \mathrm{MPa}$ to $621 \mathrm{MPa}$ as below:

$$
D I F_{y}=1+(\dot{\varepsilon} / C)^{0.227}, \text { where } C=e^{-4.7374+.0524 f_{y}-3.5908 \times 10^{-5}} f_{y}^{2}
$$

Moreover, Singh et al. [38] obtained the Cowper-Symonds material parameters for mild steel by linear curve fitting of their experimental results in the strain rate range of $5-750 \mathrm{~s}^{-1}$ and reported $C$ and $q$ to be 301 and 2.4639 , respectively. In the present study, the $D I F_{y}$ of the Grade 250 seamless steel pipes has been calculated by conducting tensile tests at quasi-static and $150 \mathrm{~mm} / \mathrm{sec}$ velocity (corresponding to a strain rate of $7.5 \mathrm{~s}^{-1}$ ) dynamic tests on standard ASTM coupons [39]. The experimental tensile $D I F_{y}$ value obtained was 1.438 , which is higher than the values predicted by the Cowper-Symonds models by Luecke et al. [37] and Singh et al. [38], which are 1.237 and 1.223, respectively. This can be attributed to the characteristics of the seamless steel tubes used, which are hot-rolled and cold-drawn, resulting in a greater strength increase at high strain-rate ranges.

$D I F_{y}$ values calculated from the test results of the hollow steel tube control specimens under compression loading are presented in Figure 4. The actual strain rate obtained during the tests was extracted (range $3.5-4 \mathrm{~s}^{-1}$ ) and the $D I F_{y}$ values obtained using the Luecke et al. 
375 [37] and Singh et al. [38] models were compared to experimental $D I F_{y}$ values, measured at 376 the proof stress $\left(f_{0.2 \%}\right)$. As this figure indicates, the experimental results show a higher 377 strength increase compared to the models. Due to the size-independency of steel, the $D I F_{y}$ 378 values do not change with an increase in steel cross-section.

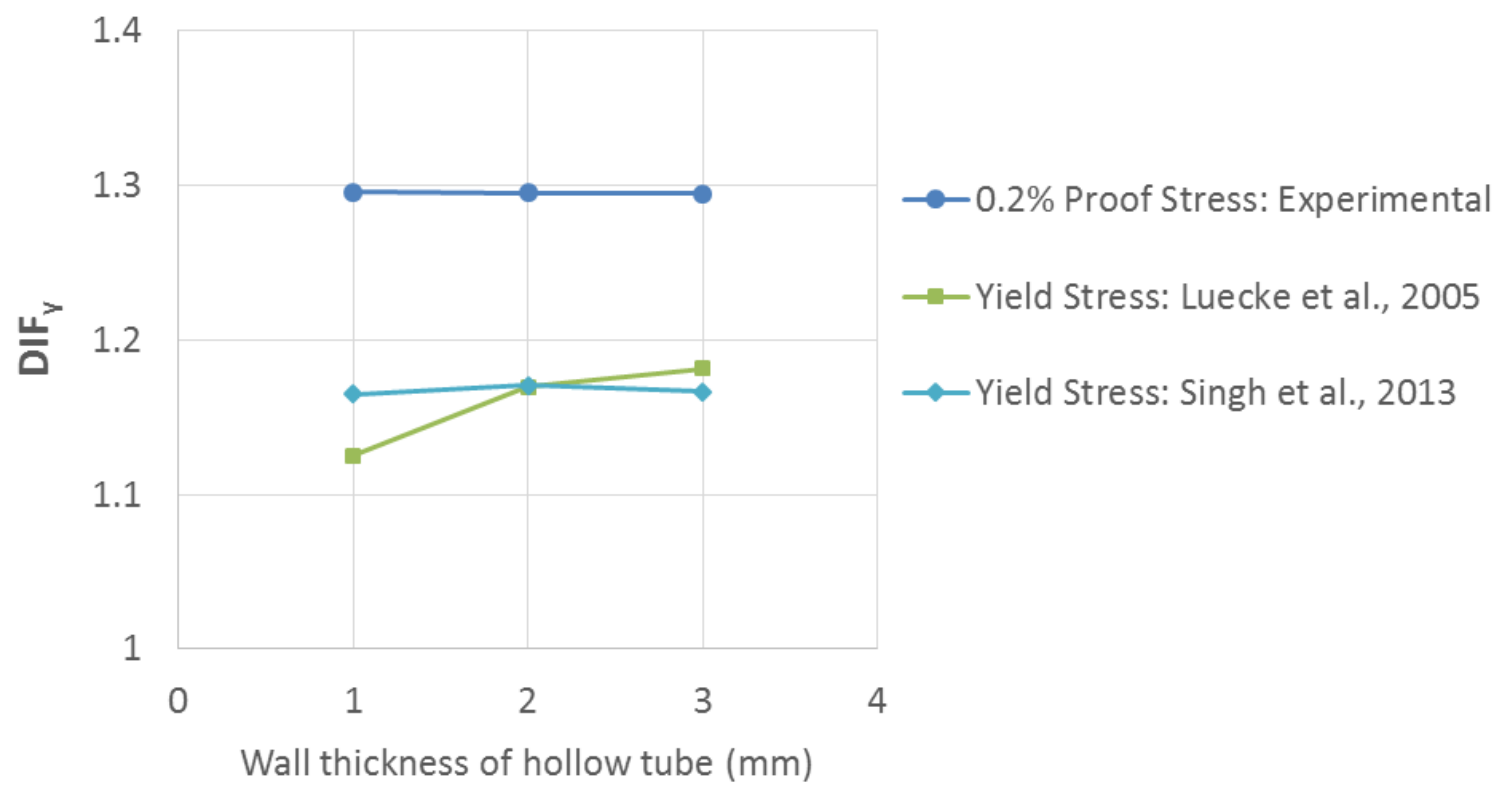

Figure 4. $\mathrm{DIF}_{\mathrm{y}}$ for $\mathrm{D}=40 \mathrm{~mm}, \mathrm{R}=1$, hollow steel tubes under compression loading

\subsection{Circular Concrete-filled Steel Tubes}

\subsubsection{Confinement effect of steel tube on concrete at quasi-static rates of strain}

The plastic resistance to compression of concrete-filled steel sections according to 385 Eurocode 4 [40] is given by a simple summation of the steel and concrete contributions, 386 without taking into consideration the concrete confinement effect, such that:

390 here, $A_{s}$ is the cross-sectional area of the circular hollow section (CHS), $A_{c}$ is the area of the concrete, $f_{y}$ is the tensile yield stress of the CHS, and $f_{c}$ is the compressive strength of concrete. Other standards, such as the ACI [28] and Australian Standards [41], use a similar 
393 formulation for calculating the squash load of a composite cross-section considering a 394 strength reduction coefficient of 0.85 for concrete [29].

395 Much research work has been done to understand the "composite action" between the 396 steel and the concrete for composite sections under axial compression. It has been confirmed 397 that circular steel tubes can provide much more effective confinement to their core concrete 398 than other shapes of hollow sections. The confinement effect has been attributed to the cross399 sectional properties as well as the material properties.

400 For concrete-filled CHSs, Eurocode 4 [40] presents a more sophisticated expression 401 allowing for an increase in strength of the concrete due to the effect of concrete 402 confinement. Provided that the relative slenderness $(\bar{\lambda})$ does not exceed 0.5 , the ultimate axial 403 capacity of concrete-filled CHS columns can be expressed by the following equation, which 404 takes into account the interaction between the steel and concrete elements through the two $405 \quad$ factors $\eta_{s}$ and $\eta_{c}$.

$406 \quad N_{C F S T}=A_{s} \eta_{s} f_{y}+A_{c} f_{c}\left[1+\eta_{c}\left(\frac{t}{D}\right)\left(\frac{f_{y}}{f_{c}}\right)\right]$, where

$407 \quad \eta_{s}=0.25(3+2 \bar{\lambda}) \quad($ which should be $\leq 1.0)$

$408 \quad \eta_{c}=4.9-18.5 \bar{\lambda}+17 \bar{\lambda}^{2} \quad($ which should be $\geq 0)$

410 where, $t$ is the wall thickness of the steel tube, $D$ is the external diameter of the steel tube, $\bar{\lambda}$ 411 is the relative slenderness, $\eta_{s}$ is the coefficient of confinement for steel and $\eta_{c}$ is the 412 coefficient of confinement for concrete. The same formulation is also adopted in AS 5100.6 413 [42] for finding the section capacity of circular composite compression members.

414 Another explanation for confinement has been proposed by Han [43], where a 415 constraining factor $\left(\xi_{s}\right)$ under quasi-static loading condition is introduced to represent the 416 composite action between the steel tube and its concrete core [44]:

$417 \quad \xi_{s}=\alpha \frac{f_{y}}{f_{c}}, \alpha=\frac{A_{s}}{A_{c}}$ 
418 where, $\alpha$ is defined as the sectional steel ratio. The confinement provided by the steel tube to

419 its core concrete increases with an increase in the constraining factor, $\xi_{s}$. If $f_{\mathrm{y}}$ and $f_{\mathrm{c}}$ are kept 420 constant, the increase in confinement depends upon $\alpha$, and hence is size-sensitive.

421 Typical stress versus axial strain curves of CFST stub columns during quasi-static 422 loading are schematically shown in Figure 5.

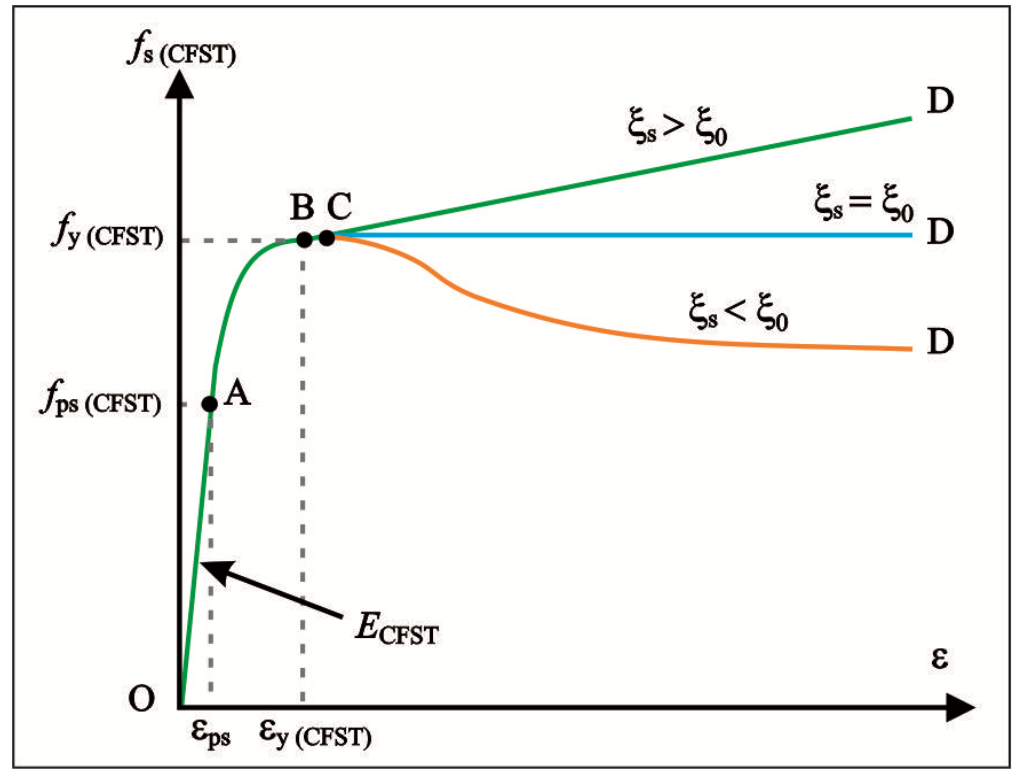

Figure 5. Schematic axial stress-strain relationship for CFST at static rates [45]

According to Han et al. [45], the curves can be categorized into 3 to 4 stages as a function of the confinement factor $\left(\xi_{s}\right)$, i.e.:

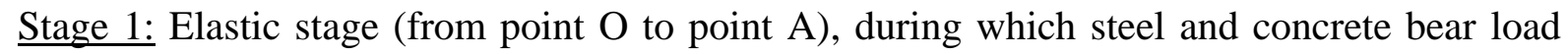
independently. At point A, yielding of steel is initiated.

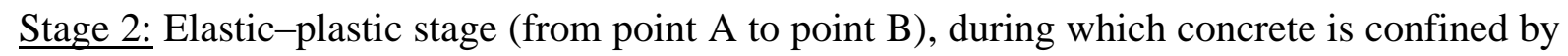
the steel tube because the Poisson's ratio of the concrete is larger than that of steel. With the increase of longitudinal deformation, confinement is enhanced.

Stage 3: Strain hardening stage (from point B to point C or from point B to point D).

During this stage, the load versus axial strain curves tend to go upwards. The shape of the curve depends on the value of the confinement factor $\left(\xi_{s}\right)$. When $\xi_{s}$ is larger than $\xi_{0}$, the curve 
437 goes up steadily to point D. When $\xi_{s}$ is less than $\xi_{0}$, the curve starts to go down after a short 438 increase to point $\mathrm{C}$. The smaller the confinement factor, the earlier the curve starts to fall. The 439 value of $\xi_{0}$ for concrete-filled steel CHS is given as 1.1 by Han et al. [45].

$440 \quad$ Stage 4: Falling stage (from point C to point D). This occurs only when the confinement 441 factor $\left(\xi_{s}\right)$ is less than $\xi_{0}$. The smaller the confinement factor, the steeper the fall of the curve. 442 For the various specimen sizes used in this study, the nominal constraining factors have been 443 calculated using Eq. 6 and are given in Table 3. The values are based on results obtained 444 from standard cylinder concrete tests (for $f_{c}$ ) and tensile coupon tests of steel tubes (for $f_{y}$ ). 445 When the CFST specimen diameter is constant, the greater the steel thickness and the higher 446 the constraining factor, $\xi_{s}$.

Table 3. Calculated constraining factors $\left(\xi_{s}\right)$ for different sample sizes

\begin{tabular}{|l|c|c|c|c|c|c|}
\hline $\begin{array}{l}\text { Nominal inner diameter of } \\
\text { tube }(\mathrm{mm})\end{array}$ & \multicolumn{3}{|c|}{40} & \multicolumn{3}{c|}{50} \\
\hline Wall thickness $(\mathrm{mm})$ & 1 & 2 & 3 & 1 & 2 & 3 \\
\hline Constraining factor $\left(\xi_{s}\right)$ & 0.50 & 1.02 & 1.56 & 0.40 & 0.81 & 1.23 \\
\hline
\end{tabular}

Stress-strain curves for quasi-static compression tests on CFST samples with different

450 wall thicknesses are presented in Figure 6. As is evident from this figure, the shape of the 451 experimental curves follows the trend of those presented by Han et al. [45]. However, the 452 value of $\xi_{0}$ is approximately 0.8 , which is less than the approximate value given in the 453 reference. This may be due to the fact that the concrete compressive strength is determined 454 from cylindrical tests herein, whereas cube tests are used by Han et al. [45]. For varying 455 diameters, the compressive strength and the strain corresponding to the maximum stress of 456 the CFST increase with the increasing confinement factor, but there is no significant change 457 to the overall ductility of the specimen. 
469 similar sizes to those of the quasi-static tests, are presented in Figure 7. Based on these

470 curves, a linear characteristic appears at the initial elastic stage until the peak stress is

471 achieved. The specimen then changes into a plastic stage, at which the curves fluctuate

472 slightly. The stress-carrying capacity of the CFST either continues to increase slowly, is 473 maintained approximately at a certain level post-initial-peak, or has an ever-decreasing stress 474 behaviour.

Figure 6. Quasi-static stress-strain relationship for concrete-filled steel tube specimens $(R=2)$ with different constraining factors $\left(\xi_{s}\right)$

\subsubsection{Confinement effect of steel tube on concrete at higher rates of strain}

The stress-strain curves for the high-strain-rate compression tests on CFST samples with

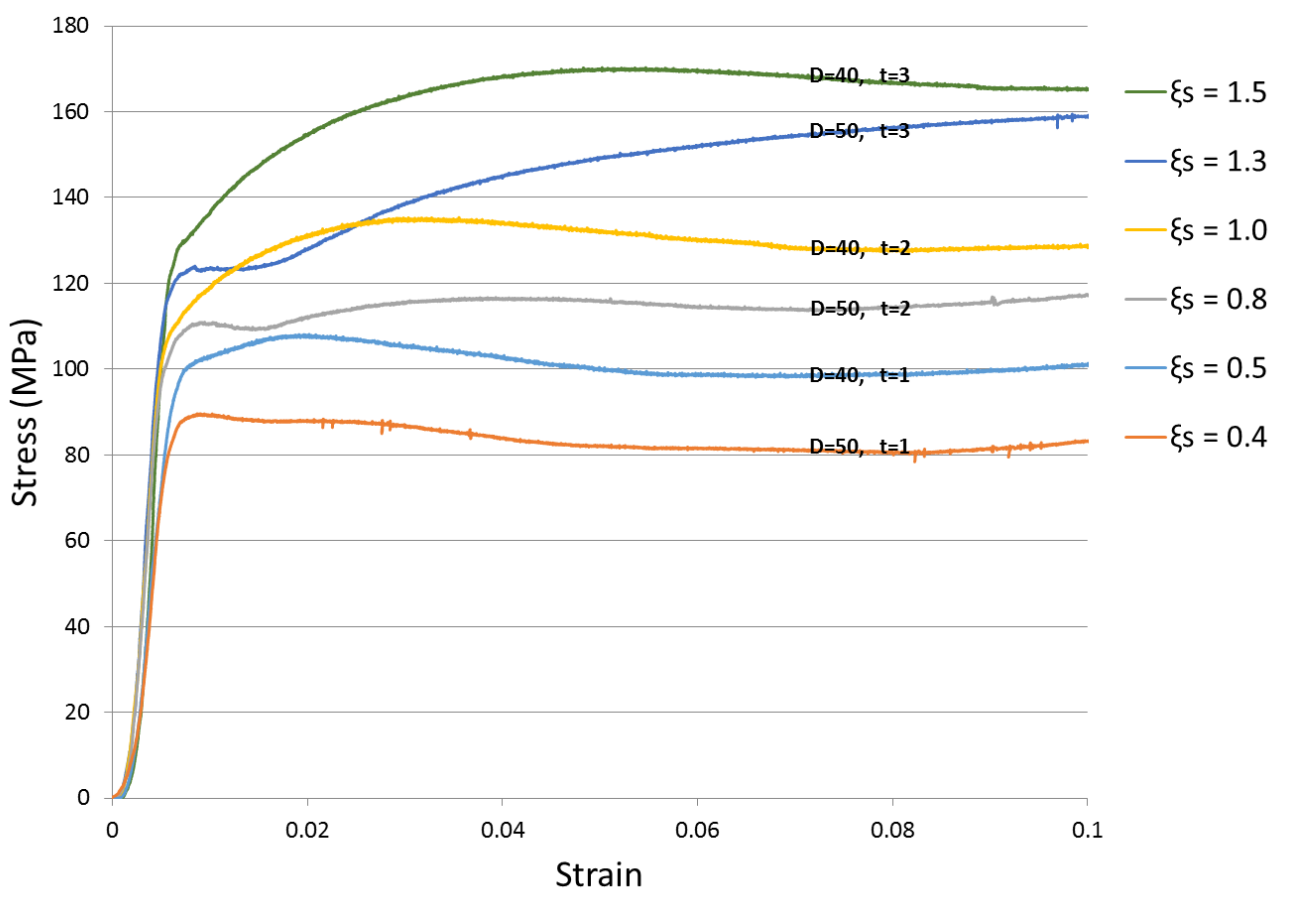




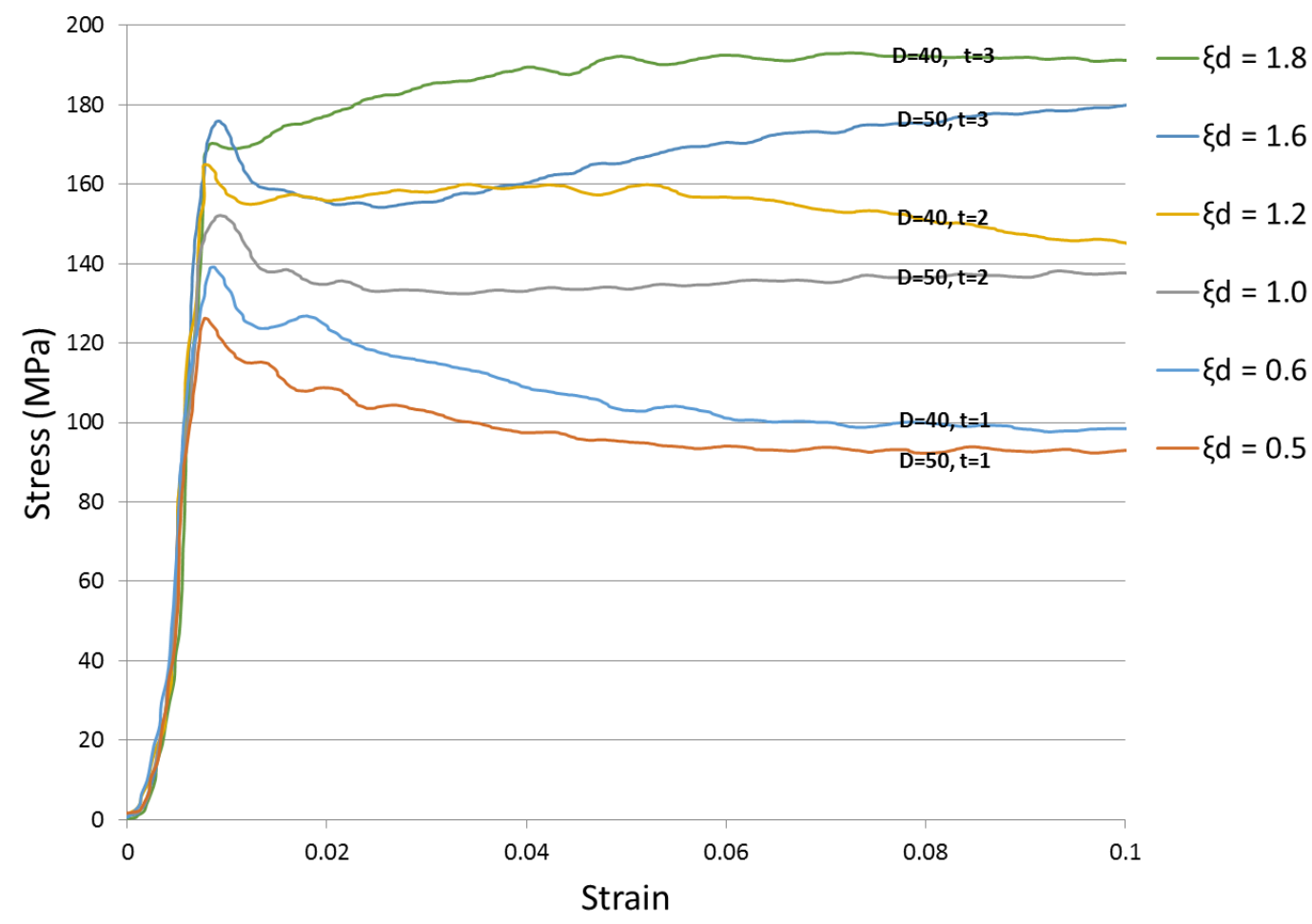

Figure 7. Impact stress-strain relationship for concrete-filled steel tube specimen $(R=2)$ with different constraining factor $\left(\xi_{d}\right)$

Due to the rate-dependent characteristic of steel, as observed in the results for the hollow tubes in the previous section, there is a pronounced increase in the strength of the steel tube under dynamic loading. Hence, it can be argued that the marked increases in stress-carrying capacities of concrete when confined with a steel tube are attributed to the effects of the strain-rate hardening of steel and the good impact behaviour of steel materials. However, with the decrease in the steel cross-section area, i.e. smaller constraining factor, there is a significant reduction in the strain hardening of steel.

It is worth noting that at high-strain-rates, the stress increase of plain concrete becomes so rapid that time is insufficient for the centre part of the specimen to expand and lateral inertia confinement is formed in the centre part. The lateral inertia confinement contributes partially to the strength increase in plain concrete at high strain rates, due to its sensitivity to lateral confinement. However, the lateral inertial confinement to the concrete core of CFST 
491 makes less contribution to the strength increase, due to the existing confinement from the 492 steel tube, which is much greater than the lateral inertia confinement [46].

493 From another point of view, as can be seen in Figure 7, the material strength increase 494 follows the trend of the static constraining factors (Figure 6). However, the shape of the 495 curves is different to those of Figure 6, since the confinement provided by the steel tube to its 496 core concrete changes under impact conditions. As seen in the previous sections, the rate 497 dependency of concrete and steel vary from one another and hence the material strength 498 enhancements due to the strain-rate effect influence the overall confinement level of the 499 CFST. To account for this, Eq. 6 can be re-written to incorporate the effect of high-strain-rate 500 loading for the calculation of constraining factors, as presented below:

$501 \quad \xi_{d}=\alpha \frac{\mathrm{f}_{\mathrm{yd}}}{\mathrm{f}_{\mathrm{cd}}}=\alpha \frac{D I F_{\mathrm{y}} \cdot \mathrm{f}_{\mathrm{y}}}{D I F_{c} \cdot \mathrm{f}_{\mathrm{c}}}$

The strain-rate effect is accounted for by using a dynamic increase factor (DIF), which is 503 defined as the ratio of strength of each material at a particular rate of dynamic strain to the 504 corresponding value at the quasi-static rate. The dynamic constraining factors calculated from 505 Eq. 10 for different sample sizes are shown in Figure 7.

506 To identify the composite action between the concrete and steel elements under impact 507 loading, schematic stress-strain curves illustrating the behaviour of CFST at high strain rates 508 are proposed. These are shown in Figure 8. This is done by adopting the main features of the 509 curves proposed by Han et al. [45] and incorporating the experimental results obtained in this 510 study. Similar to Figure 8, these curves can be categorized into 4 stages as a function of the 511 confinement factor $(\xi)$. However, while static behaviour follows three plastic paths based on 512 the value of $\xi_{0}$, due to the rate sensitivity of both steel and concrete, the dynamic behaviour is 513 definable via 4 distinctive paths which are identifiable by the two constants $\xi_{0}$ and $\xi_{1}$, as 514 illustrated in Figure 8. These constants, which differ from the static constants, can be 515 experimentally determined. 


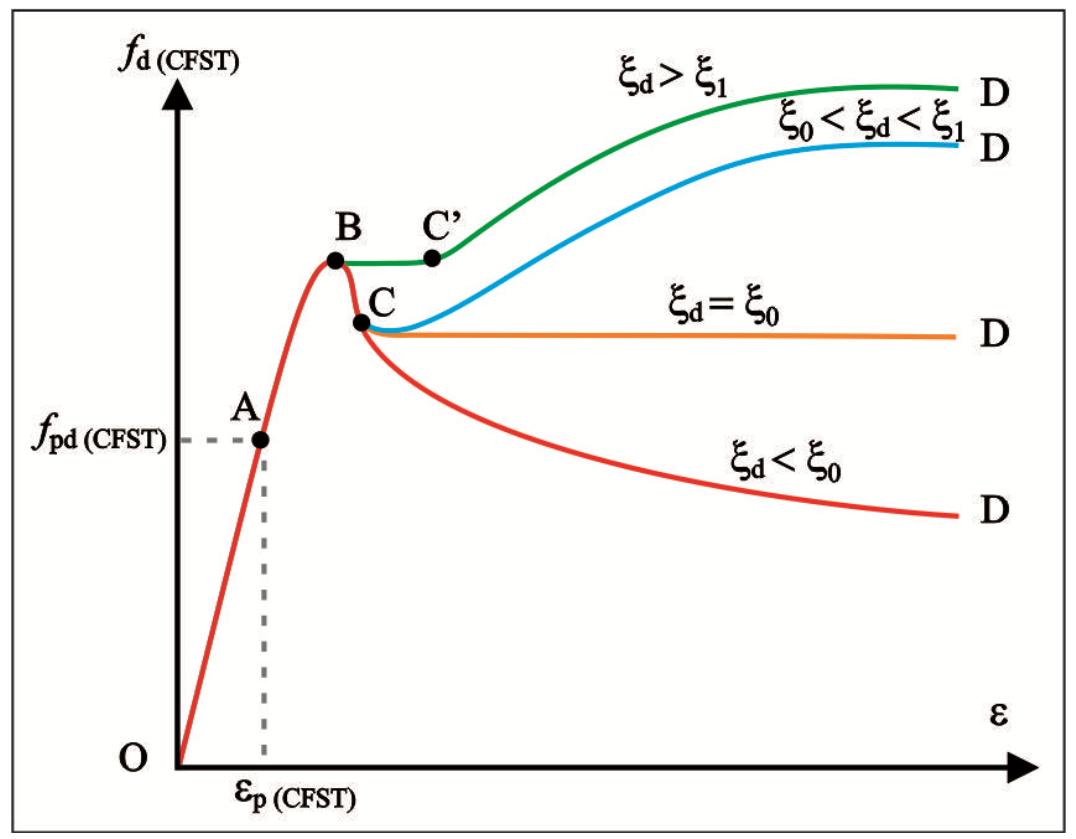

Figure 8. Proposed schematic axial stress-strain relationship for CFST at high strain rates

Based on the test results obtained in this study, the approximate dynamic values of $\xi_{0}$ and

$521 \xi_{1}$ for circular hollow tubes filled with SCC are 1.0 and 1.7, respectively.

\subsubsection{Dynamic strength increase factor of CFST}

The values for the proof stresses $\left(f_{\% 0.2}\right)$ obtained of the high-strain-rate compression 525 experiments for CFST specimen with different diameter, height/diameter ratio and wall 526 thicknesses have been demonstrated in Figure 9. This figure illustrates the stresses used in 527 calculating the dynamic impact factors henceforth as well as those used to develop theoretical 528 relations in this section to predict DIF of CFSTs. 


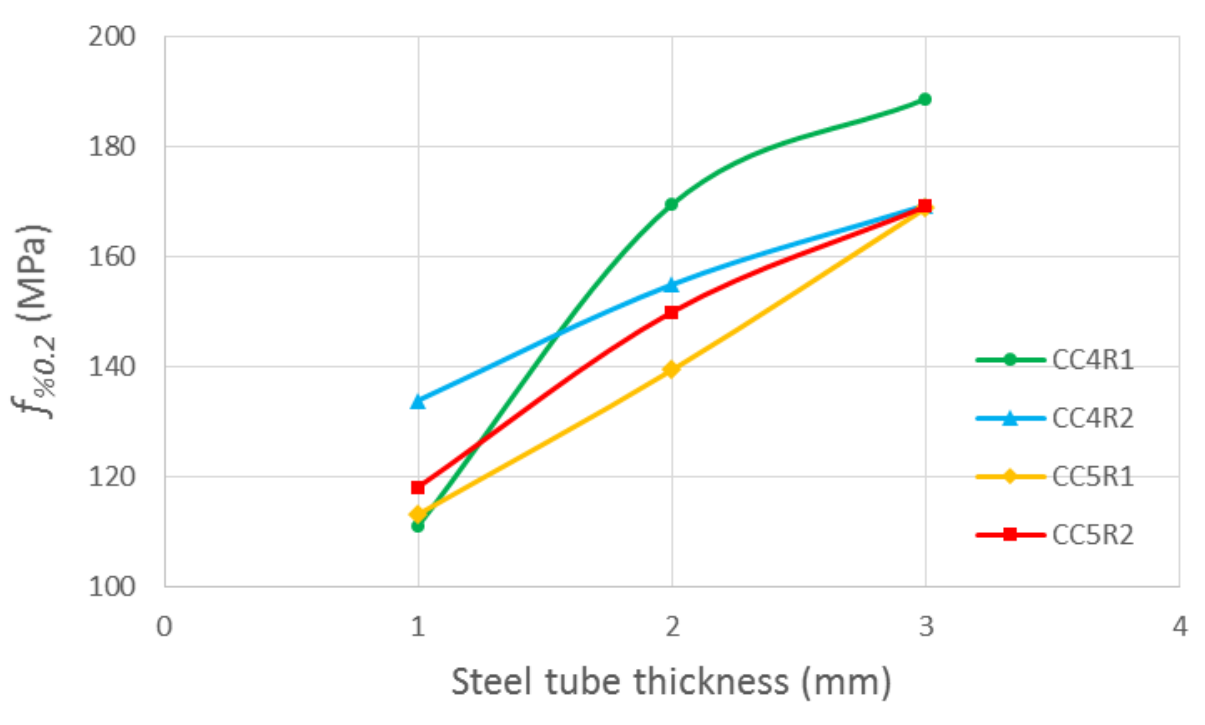

Figure 9. Proof stress $\left(f_{\% 0.2}\right)$ for $40 \mathrm{~mm}$ and $50 \mathrm{~mm}$ diameter CFST specimens with heightto-diameter $(R)$ ratios of 1 and 2 with different wall thicknesses

Furthermore, the dynamic increase factors in the average stress corresponding to various

534 average strains, for specimens with different $H / D$ and $D / t$ sizes are shown in Figure 10. Note

535 that $f_{0.2 \%}, f_{1.5 \%}, f_{2} \%, f_{5 \%}$ and $f_{10 \%}$ are the stresses corresponding to $0.2 \%, 1.5 \%, 2 \%, 5 \%$ and $536 \quad 10 \%$ specimen longitudinal strains, respectively. The engineering strains were obtained using 537 laser extensometer readings of the top and bottom of the specimen length. Since the yield 538 point is not a distinct point in the test results, it is customary to adopt and report the $0.2 \%$ 539 average proof stress as the "yield stress". 


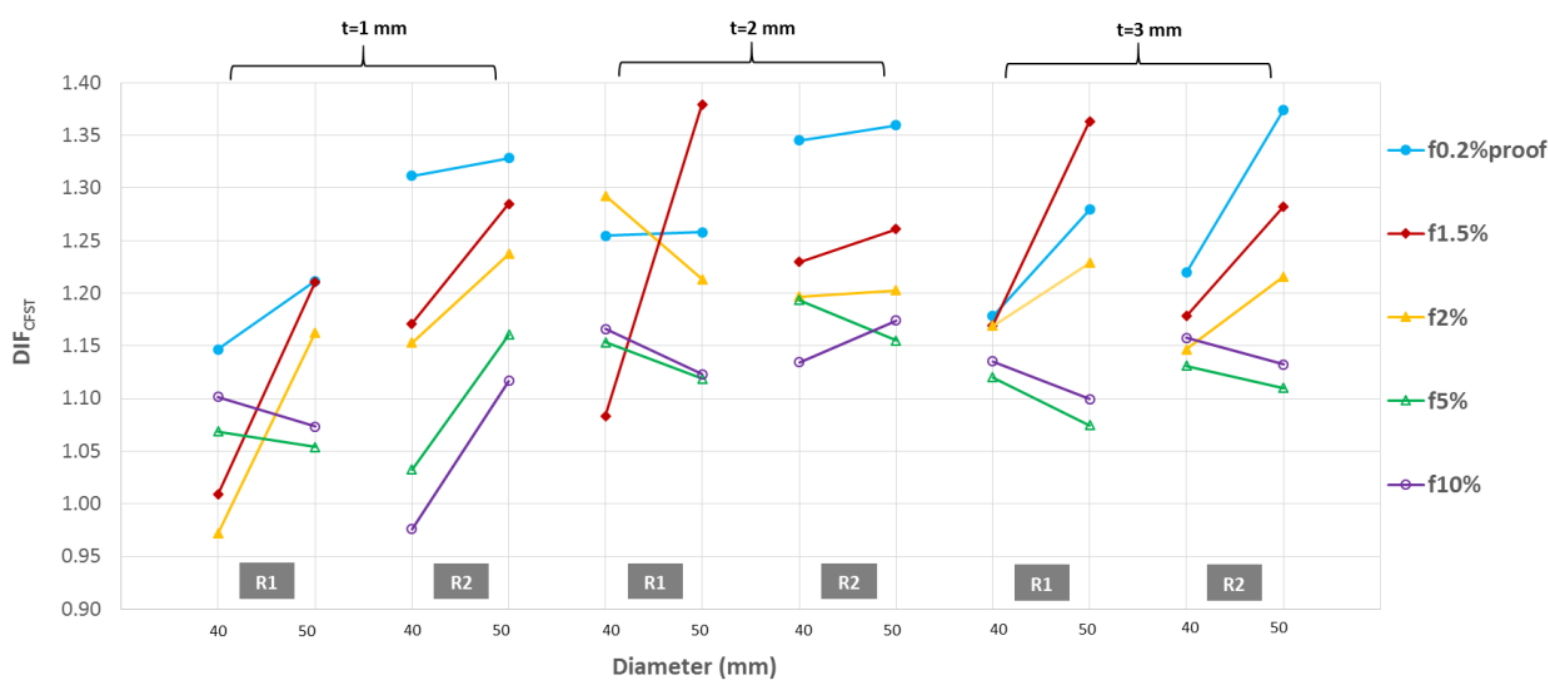

Figure 10. DIF values for $40 \mathrm{~mm}$ and $50 \mathrm{~mm}$ diameter CFST specimens with height- todiameter $(R)$ ratios of 1 and 2 with different wall thicknesses

As Figure 10 shows, generally, the dynamic strength increase for the "yield stress" $\left(D I F_{y}\right), D I F_{1.5 \%}$ and $D I F_{2 \%}$ rises with an increase in diameter. Up to $2 \%$ strains, the material is still close to the ultimate point on the stress-strain curve (point B in Figures 5 and 8) and demonstrates enhanced characteristics under impact loading. However, based on the level of confinement created by the steel tubes, a sudden drop may occur in the stress-strain curve (point $\mathrm{C}$ in Figure 8) while the static curve maintains a relatively steady plateau (point $\mathrm{C}$ in Figure 5), causing a stress decrease with the increase of cross-section dimensions.

For the same $H / D$ ratio, and the same diameter, an increase in the "yield" $D I F_{C F S T}$ is generally observed with the decrease in the $D / t$ ratio demonstrating that the increase in the rate-sensitive steel cross-section results in increased DIF for the CFST.

The concrete filling increases the limiting diameter-to-thickness ratio at which static local buckling occurs. With regard to the effect of specimen height for the same cross-sectional area, $D I F_{y}$ increases with the increase in the $H / D$ ratio, similar to those of the plain concrete results. In order to predict the increase due to dynamic effects for CFSTs, based on the assumption of simple super-position of the axial strengths of concrete infill and the steel tube, 
561 while neglecting their interaction, Xiao et al. [14] proposed the following equation to 562 calculate the $D I F$ for concrete-filled tubes:

$563 \quad D I F_{C F S T}=\frac{f_{c d} A_{c}+f_{y d} A_{s}}{f_{c S} A_{c}+f_{y} A_{s}}$

564 where, $f_{y d}$ and $f_{y}$ are the dynamic yield strength and static yield strength of steel, and $f_{c d}$ and $f_{c s}$ 565 are the dynamic and static compressive strength of concrete, respectively. The expression was 566 evaluated with tests results on 50mm diameter CFST samples with a length-to-diameter ratio 567 of 0.5 and $1 \mathrm{~mm}$ thick tubes. Tests were conducted by means of a split Hopkinson pressure 568 bar (SHPB) with strain rates ranging between 81 and $196 \mathrm{~s}^{-1}$. Xiao et al. [14] concluded that 569 neglecting the interaction mechanisms between the concrete infill and the steel tube results in 570 a considerable underestimation of the DIF for CFSTs. Hence, in the present study, an attempt 571 was made to modify Eq. 11 to include the interaction between steel and concrete elements. 572 For this purpose, Eq. 6 proposed by Eurocode 4 [40] was adopted. Moreover, the present study has been conducted on specimens of various size with the 574 intention of understanding the effect of size on the impact behaviour of CFSTs. Size effect 575 must be considered when dealing with the size-dependent component of the composite 576 element; i.e., concrete. For this purpose, Bažant's classical size-effect model [47], a 577 fundamental law in concrete studies, is employed:

$578 \quad \sigma_{N}=B \sigma_{0}\left(1+\frac{D}{D_{0}}\right)^{-1 / 2}$

579 where, $D_{0}$, also known as the characteristic size, and $B$ are constants, $\sigma_{N}$ is the nominal stress 580 at failure and $\sigma_{0}$ is the size-independent tensile strength of the material under consideration. $581 \quad D / D_{0}$ is the relative structural size ratio.

582 Based on Eqs. 11 and 12, the following rate- and size-dependent formula is proposed to 583 approximate the dynamic increase factor for the compressive strength of CFST: 
$D I F_{C F S T}=\frac{D I F_{y} f_{y d} A_{s}+D I F_{c} f_{c d} A_{c}\left[1+\eta_{C F T}\left(\frac{t}{D}\right)\left(\frac{D I F_{y} f_{y}}{D I F_{c} f_{c}}\right)\right]\left[1+\frac{H_{0} D}{H D_{0}}\right]^{-1 / 2}}{A_{s} f_{y}+A_{c} f_{c}\left[1+\left(\frac{t}{D}\right)\left(\frac{f_{y}}{f_{c}}\right)\right]\left[1+\frac{H_{0} D}{H D_{0}}\right]^{-1 / 2}}$

in which

$$
\eta_{C F T}=\frac{H}{D}(D-40.125)(D-49.89)
$$

and, $H_{0}$ is a constant and $\eta_{C F T}$ is obtained empirically using the test results. It should be emphasised that in formulating Equations 13 and 14, material strengths obtained from tests conducted on plain concrete (Section 3.1) as well as on mild steel (Section 3.2) have been utilized to predict the dynamic behaviour of composite steel-concrete CFSTs with the same sample sizes. The validity limits of Eq. 13 and Eq. 14 are $f_{y d}=430-545 \mathrm{MPa}, f_{y}=320-455$

Figure 11 compares experimental results for $D I F_{C F S T}$ to calculated values of $D I F_{C F S T}$

$$
\mathrm{MPa}, f_{c d}=50-70 \mathrm{MPa}, f_{c}=50-65 \mathrm{MPa}, D / t=13-50 \text {, and } H / D=1-2 .
$$

600 based on the formula by Xiao et al. [14] and the proposed expression (Eq. 14).

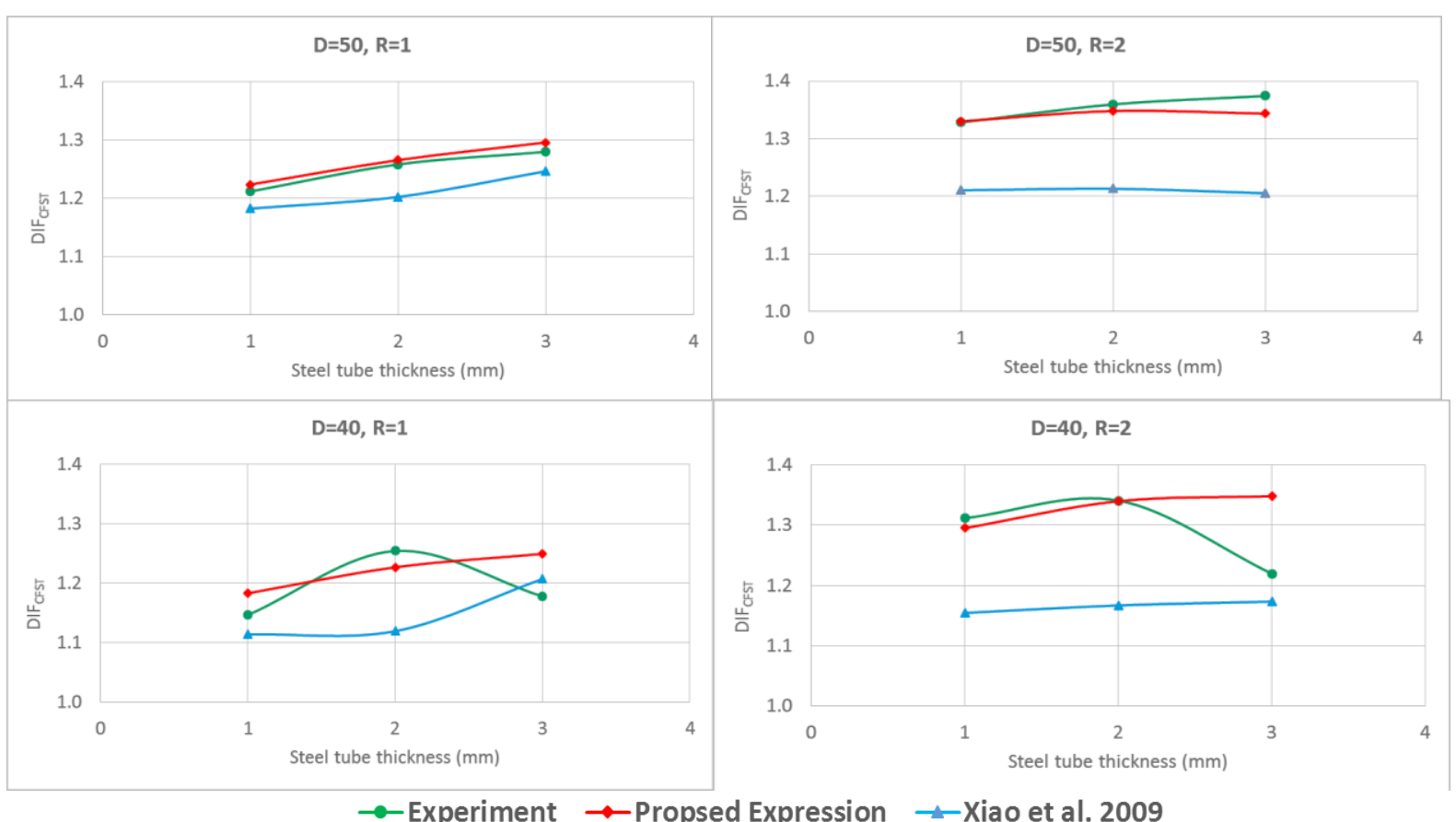

Figure 11. Comparison between experimental values of $D I F_{C F S T}$ with values calculated using 606 Eq. (13) and Xiao et al.'s [14] formula 
As can be seen from the figure, the proposed expression exhibits a better correlation with 608 the experimental results, especially for the larger diameter samples. However, for $40 \mathrm{~mm}$ 609 diameter samples with $3 \mathrm{~mm}$ thickness there is a large difference between the two proposed $610 D I F_{C F S T}$ values and the formula of Xiao et al. [14] is closer to experimental results. This 611 shows that in the case of higher constraining factors (Figures 6 and 7), the interaction effect 612 between steel and concrete and the composite behavior become more dominant, resulting in 613 the simple superposition seemingly presenting a better prediction for the dynamic increase 614 factor.

615 In addition to the $D I F_{C F S T}$ formula above (Eq. 13), an attempt was also made to present 616 an empirical expression for predicting the DIF of CFSTs at lower impact rates of strain $617\left(\dot{\varepsilon} \leq 5 s^{-1}\right)$. The lower strain rates $\left(\leq 5 s^{-1}\right)$ were found in field blast testing on steel hollow 618 sections and concrete-filled steel hollow sections [48, 49]. The empirical equations derived 619 here may be adopted in commercial finite element software packages such as LS-DYNA. For 620 this purpose, the DIF for the proof stress of CFSTs is presented in a form close to that of the 621 Cowper-Symonds equation (Eq. 3) for steel. However, the strength and cross-sectional 622 dimensions of both constituent materials are incorporated in the relationship as follows:

$$
D I F_{C F S T}=C\left(\dot{\varepsilon} / \dot{\varepsilon}_{0}\right)^{P . \beta} \quad \text { for } \quad 1 \leq \dot{\varepsilon} \leq 5 S^{-1}
$$

$624 P=\left(f_{c s} A_{c}+f_{y} A_{s}\right) /\left(f_{y} A_{s}\right)$

625 where, the increase in the proof stress with strain rate is described using two parameters, $C$ 626 and $\beta$ and $\dot{\varepsilon}_{0}=1 \mathrm{~s}^{-1}$. Taking the natural algorithm of each side produces the linear equation:

$627 \quad \ln \mathrm{DIF}_{C F S T}=\ln \mathrm{C}+P \cdot \beta \ln \left(\dot{\varepsilon} / \dot{\varepsilon}_{0}\right)$

628 Plotting the log-log data (Figure 12), the constants are found and hence Eq. (16) can be 629 written as:

$630 D I F_{C F S T}=e^{b}\left(\dot{\varepsilon} / \dot{\varepsilon}_{0}\right)^{P . \beta}$, where $\beta=-5.31 \times 10^{-2}$ and $b=0.3336$ 
631 Note that the two data points corresponding to the DIF of $40 \mathrm{~mm}$ samples with $3 \mathrm{~mm}$ steel 632 tube thickness have not been considered in the data points shown in Figure 12. Incorporation 633 those two would reduce the values of $\beta$ and $b$ to $-4.83 \times 10^{-2}$ and 0.31 , respectively.

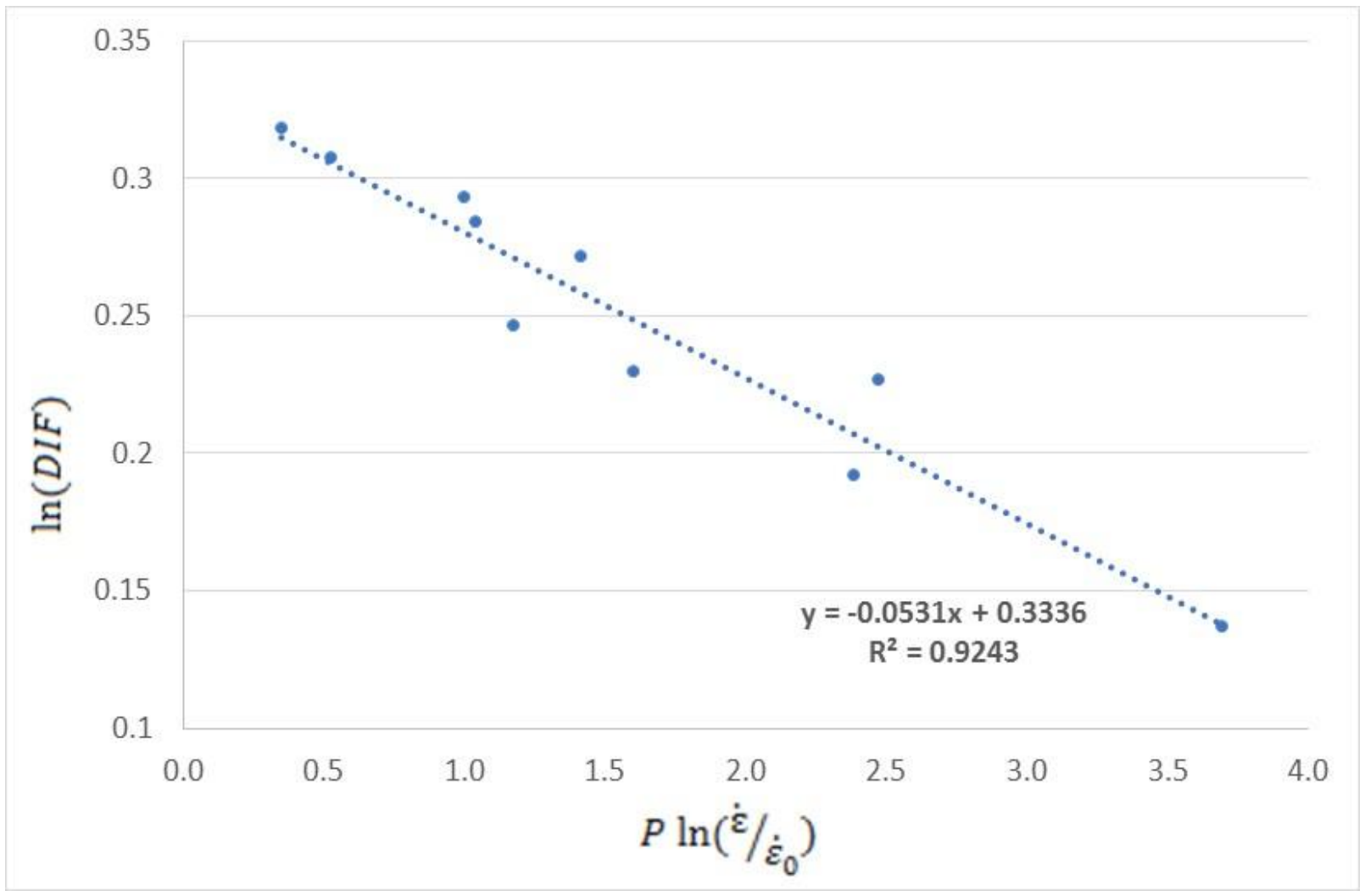

Figure 12. Determination of the parameters $C$ and $\beta$ using a linear regression fit to experimental data

\subsubsection{Failure modes of CFST}

The failure modes of CFST specimens, as shown in Figure 13, demonstrate that the

641 failure mechanism of the specimens involve local buckling of the outer steel tube (outward

642 folding), which was also observed by Yu et al. [17]. After local buckling occurs, most of the

643 increase in deformation is concentrated in the buckled region. Since the compression load 644 causes the steel tube to expand faster than the concrete, it is the circumferential ring bulge of 645 the steel tube that appears initially and minor cracks can only be identified on the concrete 
647 (Figure 13(a)).

648

649

650

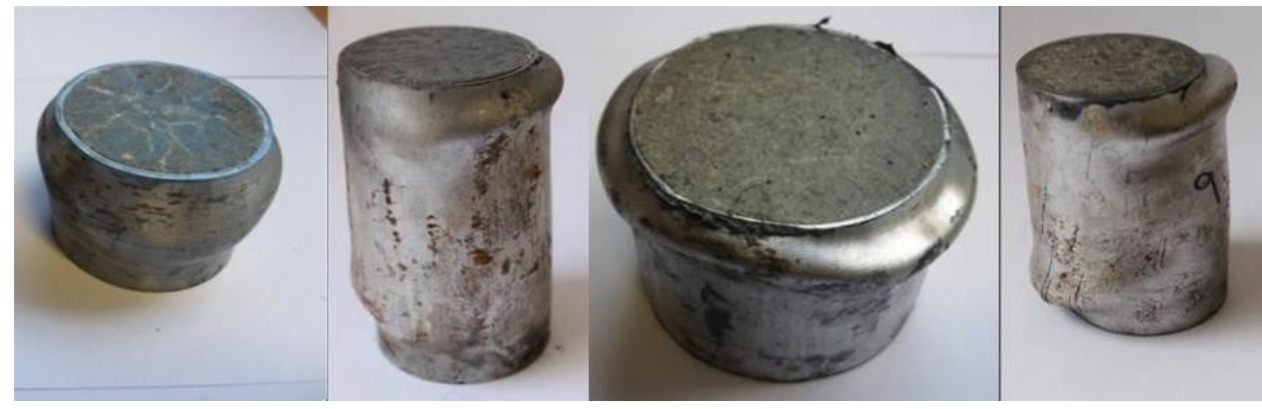

(a) (c)

Figure 13. Failure mode of confined concrete under static loading with sample aspect ratio (a) $\mathrm{R}=1$, (b) $\mathrm{R}=2$ and impact loading with sample aspect ratio (c) $\mathrm{R}=1$, (d) $\mathrm{R}=2$

There is no obvious difference between the failure modes of different sizes of specimens with the same $H / D$ ratio. For $H / D=1$, and both loading scenarios, most buckling failures occur near either the top or bottom of the specimen (Figure 13 (a), (c)). However, for $H / D=2$ the buckling occurs generally at both ends of the specimen height. Considering confined samples with 50mm diameter in all thicknesses, symmetrical elephant-foot buckling occurs in the static tests with radial concrete cracks. However, under impact loading, asymmetrical bucking of the steel occurs at the top of the specimen with inclined bulges (Figure 13 (c), (d)). As the thickness increases, samples have a more symmetrical buckle-shape failure. Compared to those in the static tests, cracks under high-strain-rate loading are non-radial and non-nucleated.

\section{CONCLUSIONS}

The aim of this research was to investigate the effect of size on the impact response of concrete-filled mild steel tube stub-column samples. For this purpose, cylindrical samples 
667 with different height-to-diameter (H/D) and diameter-to-thickness (D/t) ratios were cast and 668 tested. Samples of the same size of plain concrete and hollow tubes were adopted as control 669 tests. The influence of end friction and curing conditions was also investigated for plain $670 \quad$ concrete.

671 The stress-strain behaviour of CFSTs under high-strain-rate loading was found to be a 672 function of the amount of confinement that the steel component imposes on the concrete. The 673 Dynamic Increase Factor $(D I F)$ for CFSTs and the constituent materials have been 674 experimentally derived and compared to the values calculated using DIF models proposed in 675 the literature. New size- and rate-dependent expressions, as well as an empirical rate676 dependent formula, are proposed for obtaining the material strength increase of CFSTs subject to high-strain-rate loading. The proposed expressions show a good correlation with 679 literature.

680 The following behavioural aspects have been deduced:

- The size dependency of the DIF of compressive strength of self-compacting concrete is confirmed: the larger the aspect ratio of the samples, the higher the DIF values. - The higher the friction level of the end-boundary conditions, the higher the DIF values;

- The DIF of CFSTs is proven to be size-dependent. The dynamic increase factor for yield stress $\left(D I F_{y}\right)$ has been found to increase with increasing $H / D$ ratio and decrease with increasing $D / t$; of CFST at impact rates;

- The failure mode of CFST specimens is mainly dominated by one mode: the appearance of concrete cracks together with local bulging of circumferential steel. 


\section{ACKNOWLEDGMENTS}

The work presented in this research is supported by the Australian Research Council through a Discovery Project (DP130100181) and Tsinghua Initiative Scientific Research Program (No.20131089347). The authors acknowledge the help and support of graduate student Ms. Shaohua Zhang as well as the technical staff: Mr Long Goh and Mr Zoltan of the Monash Civil Engineering Laboratory, and Mr Graeme Burnett and Mr Michael Culton of the Smart Structures Laboratory at Swinburne University of Technology.

\section{REFERENCES}

1. Mirmomeni, M., Heidarpour, A., Zhao, X.-L., Hutchinson, C.R., Packer, J.A. and Wu, C., Mechanical properties of partially damaged structural steel induced by high strain rate loading at elevated temperatures - An experimental investigation. International Journal of Impact Engineering, 2015. 76(0): p. 178-188.

2. Song, Q.-Y., Heidarpour, A., Zhao, X.-L. and Han, L.-H., Performance of DoubleAngle Bolted Steel I-Beam to Hollow Square Column Connections Under Static and Cyclic Loadings. International Journal of Structural Stability and Dynamics, 2014: p. 1450098.

3. Sinaie, S., Heidarpour, A., Zhao, X.L., Sanjayan, J.G., Effect of size on the response of cylinderical concrete samples under cylic loading. Construction and Building Materials, 2015. 84: p. 399-408.

4. Nassirnia, M., Heidarpour, A., Zhao, X.-L. and Minkkinen, J., Innovative hollow corrugated columns: A fundamental study. Engineering Structures, 2015. 94(0): p. 4353.

5. Javidan, F., Heidarpour, A., Zhao, X.-L. and Minkkinen, J., Performance of innovative fabricated long hollow columns under axial compression. Journal of Constructional Steel Research, 2015. 106(0): p. 99-109.

6. Azhari, F., Heidarpour, A., Zhao, X.-L. and Hutchinson, C.R., Mechanical properties of ultra-high strength (Grade 1200) steel tubes under cooling phase of a fire: An experimental investigation. Construction and Building Materials, 2015. 93: p. 841850.

7. Hosseini, S., Heidarpour, A., Collins, F. and Hutchinson, C.R., Effect of strain ageing on the mechanical properties of partially damaged structural mild steel. Construction and Building Materials, 2015. 77(0): p. 83-93. 
8. Heidarpour, A. and Bradford, M.A., Beam-column element for non-linear dynamic analysis of steel members subjected to blast loading. Engineering Structures, 2011. 33(4): p. 1259-1266.

9. Farahi, M., Heidarpour, A., Zhao, X.-L. and Al-Mahaidi, R., Compressive behaviour of concrete-filled double-skin sections consisting of corrugated plates. Engineering Structures, 2016. 111: p. 467-477.

10. Elfahal, M.M., Krauthammer, T., Ohno, T., Beppu, M. and Mindess, S., Size effect for normal strength concrete cylinders subjected to axial impact. International Journal of Impact Engineering, 2005. 31(4): p. 461-481.

11. Bischoff, P. and Perry, S., Impact Behavior of Plain Concrete Loaded in Uniaxial Compression. Journal of Engineering Mechanics, 1995. 121(6): p. 685-693.

12. Huo, J., Zheng, Q., Chen, B. and Xiao, Y., Tests on impact behaviour of microconcrete-filled steel tubes at elevated temperatures up to $400^{\circ} \mathrm{C}$. Materials and Structures, 2009. 42(10): p. 1325-1334.

13. Prichard, S.J. and Perry, S.H., The impact behaviour of sleeved concrete cylinders. Structural Engineer, 2000. 78(17): p. 23-7.

14. Xiao, Y., Shan, J., Zheng, Q., Chen, B. and Shen, Y., Experimental Studies on Concrete Filled Steel Tubes under High Strain Rate Loading. Journal of Materials in Civil Engineering, 2009. 21(10): p. 569-577.

15. Li, Z.-B., Song, J., Du, X.-L. and Yang, X.-G., Size effect of confined concrete subjected to axial compression. Journal of Central South University, 2014. 21(3): p. 1217-1226.

16. Ross, C.A., Jerome, D.M., Tedesco, J.W. and Hughes, M.L., Moisture and Strain Rate Effects on Concrete Strength. Materials Journal, 1996. 93(3).

17. Yu, Q., Tao, Z. and $\mathrm{Wu}, \mathrm{Y} . \mathrm{X}$. ., Experimental behaviour of high performance concrete-filled steel tubular columns. Thin-Walled Structures, 2008. 46(4): p. 362370.

18. Hao, Y., Hao, H., Jiang, G.P. and Zhou, Y., Experimental confirmation of some factors influencing dynamic concrete compressive strengths in high-speed impact tests. Cement and Concrete Research, 2013. 52(0): p. 63-70.

19. Huo, J., He, Y. and Chen, B., Experimental study on impact behaviour of concretefilled steel tubes at elevated temperatures up to 800 C. Materials and Structures, 2014. 47(1-2): p. 263-283.

20. Domone, P., Self-compacting concrete: An analysis of 11 years of case studies. Cement and Concrete Composites, 2006. 28(2): p. 197-208.

21. Persson, B. Creep, shrinkage and elastic modulus of self-compacting concrete. in 1st International RILEM Symposium on Self-Compacting Concrete. 1999. Stockholm, Sweden: RILEM Publications. p:239-250.

22. The European Guidelines for Self-Compacting Concrete Specification, Production and Use. 2005, Citeseer: http://www.efnarc.org/pdf/SCCGuidelinesMay2005.pdf.

23. ACI-211.1, Standard Practice for Selecting Proportions for Normal, Heavyweight, and Mass Concrete. American Concrete Institute, , 1991.

24. AASHTO-T84, Specific Gravity And Absorption of Fine Aggregate. American Association of State Highway and Transportation Officials, 2010.

25. ASTM-C618, Standard Specification for Coal Fly Ash and Raw or Calcined Natural Pozzolan for Use as a Mineral Admixture in Concrete. 2012: ASTM International.

26. AS-1391, Metallic materials - Tensile testing at ambient temperature. Standards Australia, Sydney, 2007.

27. ASTM-C512, Standard Test Method for Creep of Concrete in Compression. 2012: ASTM International. 
28. ACI-318-05, Building code requirements for structural concrete. American Concrete Institute, 2005.

29. Giakoumelis, G. and Lam, D., Axial capacity of circular concrete-filled tube columns. Journal of Constructional Steel Research, 2004. 60(7): p. 1049-1068.

30. CEB, Concrete structures under impact and impulsive loading, in Bulletin d'Information No. 187. 1988, Comite Euro-International du Beton: Lausanne, France.

31. Bischoff, P.H. and Perry, S.H., Compressive behaviour of concrete at high strain rates. Materials and structures, 1991. 24(6): p. 425-450.

32. Del Viso, J., Carmona, J. and Ruiz, G., Shape and size effects on the compressive strength of high-strength concrete. Cement and Concrete Research, 2008. 38(3): p. 386-395.

33. Aitcin, P.-C., Miao, B., Cook, W.D. and Mitchell, D., Effects of size and curing on cylinder compressive strength of normal and high-strength concrete. Materials Journal, 1994. 91(4): p. 349-355.

34. Zhao, H., Sun, W., Wu, X. and Gao, B., Effect of initial water-curing period and curing condition on the properties of self-compacting concrete. Materials \& Design, 2012. 35: p. 194-200.

35. Cowper, G.R. and Symonds, P.S., Strain-hardening and strain-rate effects in the impact loading of cantilever beams. 1957, DTIC Document.

36. Sun, M. and Packer, J.A., High strain rate behaviour of cold-formed rectangular hollow sections. Engineering Structures, 2014. 62-63(0): p. 181-192.

37. Luecke, W.E., McColskey, J.D., McCowan, C.N., Banovic, S.W., Fields, R.J., Foecke, T., Siewert, T.A. and Gayle, F.W., Mechanical Properties of Structural Steels. Federal Building and Fire Safety Investigation of the World Trade Center Disaster. The National Institute of Standards and Technology (NIST), U.S. Department of Commerce, 2005.

38. Singh, N., Cadoni, E., Singha, M. and Gupta, N., Dynamic Tensile and Compressive Behaviors of Mild Steel at Wide Range of Strain Rates. Journal of Engineering Mechanics, 2013. 139(9): p. 1197-1206.

39. ASTM-E8, Standard Test Methods for Tension Testing of Metallic Materials. American Society of Testing and Materials, 2011.

40. Eurocode-4, Design of composite steel and concrete structures. Part 1-1: General rules and rules for buildings2004, 1994.

41. AS-4100, Steel structures. Standards Australia, Sydney, 1998.

42. AS-5100.6, Bridge design-Steel and composite construction. Standards Australia, Sydney, 2004.

43. Han, L.-H., Fire resistance of concrete filled steel tubular columns. Advances in Structural Engineering-An International Joumal, 1998. 2(1): p. 35-39.

44. Zhao, X.-L., Han, L.-H. and Lu, H., Concrete-filled tubular members and connections. 2010: Taylor \& Francis, Abingdon, UK.

45. Han, L.-H., Yao, G.-H. and Zhao, X.-L., Tests and calculations for hollow structural steel (HSS) stub columns filled with self-consolidating concrete (SCC). Journal of Constructional Steel Research, 2005. 61(9): p. 1241-1269.

46. Xiao, Y., Zheng, Q., Huo, J., Shan, J. and Chen, B., Strength of Concrete Filled Steel Tubes under High-Strain Rate Loading, in Composite Construction in Steel and Concrete VI. 2011, ASCE Publications. p. 291-303.

47. Bažant, Z., Size Effect in Blunt Fracture: Concrete, Rock, Metal. Journal of Engineering Mechanics, 1984. 110(4): p. 518-535. 
824

825

826

827

828

829

830

831

832

833

48. Ritchie, C., Packer, J.A., Seica, M. and Zhao, X.L. Field blast testing and FE modelling of RHS members. in The 15th International Symposium on Tubular Structures. 2015. Rio, Brazil: CRC Press.

49. Ritchie, C., Packer, J., Seica, M. and Zhao, X. Field blast testing and FE modelling of concrete-filled RHS members. in The 3rd International Conference on Protective Structures (ICPS3). 2015. Newcastle, NSW: School of Engineering, The University of Newcastle. 